Supporting Information for:

\title{
NMR and EPR Studies of Low-Spin Fe(III) Complexes of meso- Tetra-(2,6-Disubstituted Phenyl)Porphyrinates Complexed to \\ Imidazoles and Pyridines of Widely Differing Basicities
}

\author{
C. Todd Watson, ${ }^{\dagger}$ Sheng Cai ${ }^{\dagger}$ Nikolai V. Shokhirev and F. Ann Walker*
}

Table S1. ${ }^{1} \mathrm{H}$ Chemical Shifts of Free-Base Porphyrins at Ambient Temperature in $\mathrm{CDCl}_{3} .{ }^{56}$

$\begin{array}{lclccc}\begin{array}{l}\text { Free-Base } \\ \text { Porphyrin }\end{array} & \begin{array}{c}\text { B-pyrrole-H } \\ (\mathrm{ppm})\end{array} & \begin{array}{c}\text { para-H} \\ (\mathrm{ppm})\end{array} & \begin{array}{c}\text { meta-H} \\ (\mathrm{ppm})\end{array} & \begin{array}{c}\text { ortho-H } \\ (\mathrm{ppm})\end{array} & \begin{array}{c}\mathrm{N}-\mathrm{H} \\ (\mathrm{ppm})\end{array} \\ \mathrm{TMPH}_{2} & 8.61 & 2.62^{*} & 7.26 & 1.85^{*} & -2.75 \\ \left(2,6-\mathrm{Cl}_{2}\right)_{4} \mathrm{TPPH}_{2} & 8.67 & 7.73 & 7.78 & & -2.53 \\ \left(2,6-\mathrm{Br}_{2}\right)_{4} \mathrm{TPPH}_{2}{ }^{\dagger} & 8.82 & 8.25 & 7.83 & & -2.38 \\ \left(2,6-(\mathrm{OMe})_{2}\right)_{4} \mathrm{TPPH}_{2} & 8.67 & 7.68 & 6.96 & 3.49 * & -2.50 \\ & & & & & \\ * \text { Methyl protons } & & & & & \\ { }^{\dagger} \text { In DMF- } d_{7} \text {. } & & & & & \end{array}$


Table S2. ${ }^{1} \mathrm{H}$ Chemical Shifts for the Tetrakis-(2,6-disubstituted phenyl)porphyrinatoiron(III) Chloride Complexes at Ambient Temperature in $\mathrm{CDCl}_{3} .{ }^{56}$

$\begin{array}{lccc}\begin{array}{l}\text { Porphyrinatoiron(III) } \\ \text { Chloride }\end{array} & \begin{array}{c}\beta \text {-pyrrole-H } \\ (\mathrm{ppm})\end{array} & \begin{array}{c}\text { para-H } \\ (\mathrm{ppm})\end{array} & \begin{array}{c}\text { meta-H } \\ (\mathrm{ppm})\end{array} \\ \mathrm{TMPFeCl} & 81 & 4.2 & 16.2 \\ & & & 14.5 \\ \left(2,6-\mathrm{Cl}_{2}\right)_{4} \mathrm{TPPFeCl} & 81 & 8.2 & 14.1 \\ & & & 12.8 \\ \left(2,6-\mathrm{Br}_{2}\right)_{4} \mathrm{TPPFeCl} & 81 & 8.2 & 13.7 \\ & & & 12.6 \\ \left(2,6-(\mathrm{OMe})_{2}\right)_{4} \mathrm{TPPFeCl} & 81 & * & 11.8\end{array}$

*Peaks not discernable above noise due to insolubility of $\left(2,6-(\mathrm{OMe})_{2}\right)_{4} \mathrm{TPPFeCl}$ in most solvents.

Table S3. ${ }^{1} \mathrm{H}$ Chemical Shifts for the Tetrakis-(2,6-disubstituted phenyl)porphyrinatoiron(III) Perchlorate Complexes at Ambient Temperature in $\mathrm{CDCl}_{3} .{ }^{56}$

$\begin{array}{lccc}\begin{array}{l}\text { Porphyrinatoiron(III) } \\ \text { Perchlorate }\end{array} & \begin{array}{c}\beta \text {-pyrrole-H } \\ (\mathrm{ppm})\end{array} & \begin{array}{c}\text { para-H } \\ (\mathrm{ppm})\end{array} & \begin{array}{c}\text { meta-H } \\ (\mathrm{ppm})\end{array} \\ \mathrm{TMPFeOClO}_{3} & -4.4 & 4.0 * & 11.7 \\ \left(2,6-\mathrm{Cl}_{2}\right)_{4} \mathrm{TPPFeOClO}_{3} & 40.0 & 9.0 & 13.1 \\ \left(2,6-\mathrm{Br}_{2}\right)_{4} \mathrm{TPPFeOClO}_{3} & 30.9 & 9.2 & 12.4 \\ \left(2,6-\mathrm{F}_{2}\right)_{4} \mathrm{TPPFeOClO}_{3} & \sim 15 & & \\ \left(2,6-(\mathrm{OMe})_{2}\right)_{4} \mathrm{TPPFeOClO}_{3} & \sim-16 & & \\ & & & 10.6 \\ * \text { Methyl shift. } & & \end{array}$




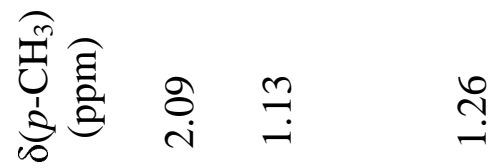

䨌高

$\frac{9}{6} 5$

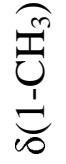

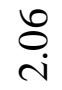

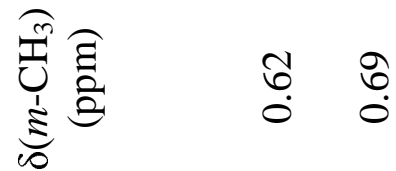

善量量

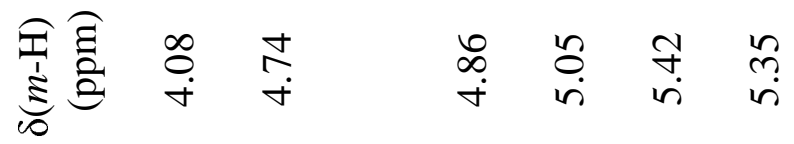

善高哭

衰

范

总

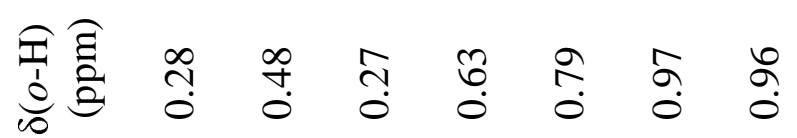

퐇

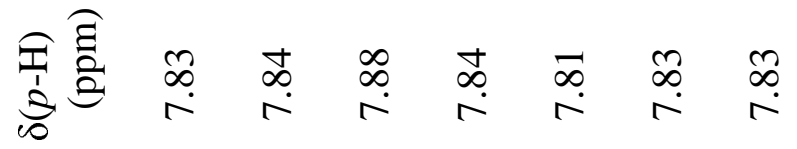

品

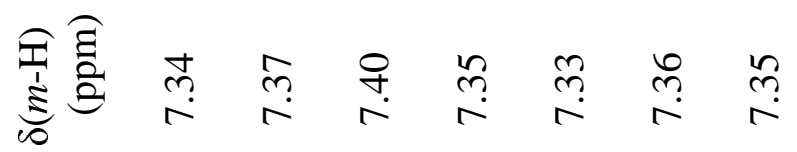

इ

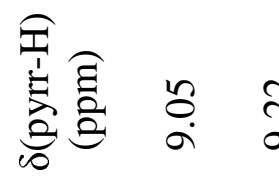

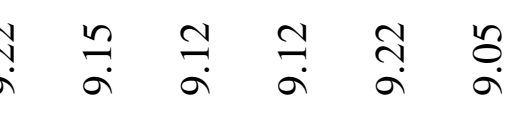

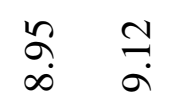

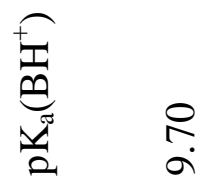

สู่

$\stackrel{0}{n}$ 


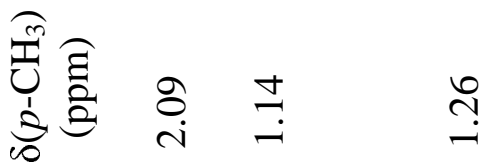

譥高

둥 $\frac{9}{6}$

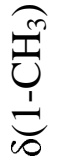

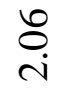

预言

善品虽

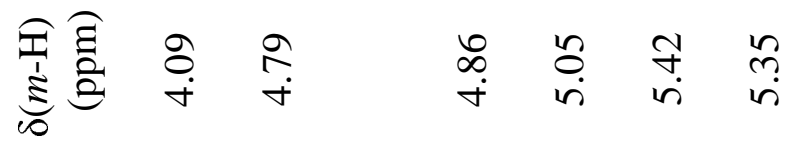

善器焉

戛高

$\stackrel{\substack{1 \\ 0}}{\infty}$

胥

䑻言

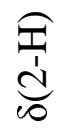

$\stackrel{8}{\circ}$

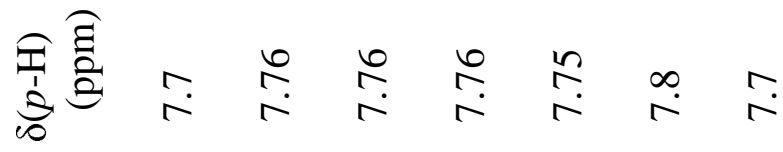

$\stackrel{\infty}{\sim}$

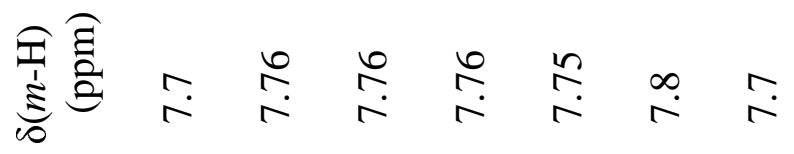

$\stackrel{\infty}{\sim}$

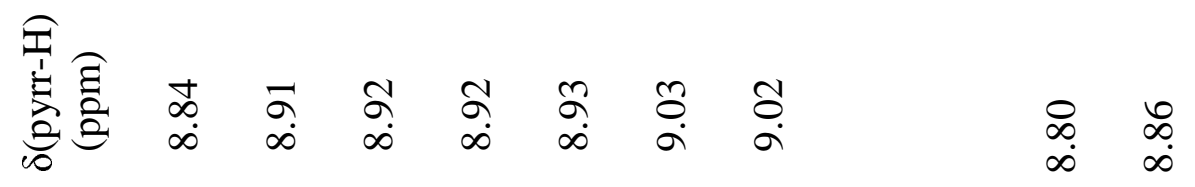

舀

สุ ๆ ๆ

$\stackrel{n}{n} \stackrel{m}{n}$

官

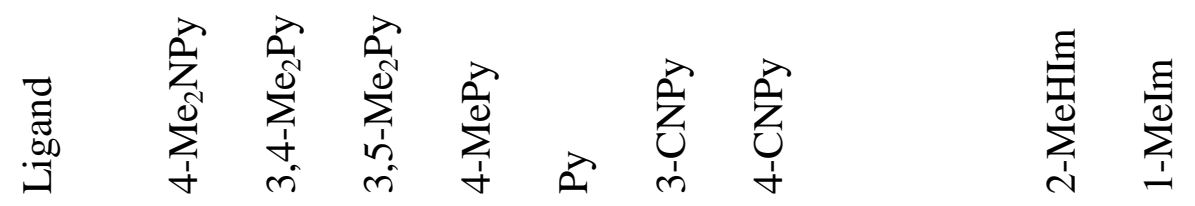




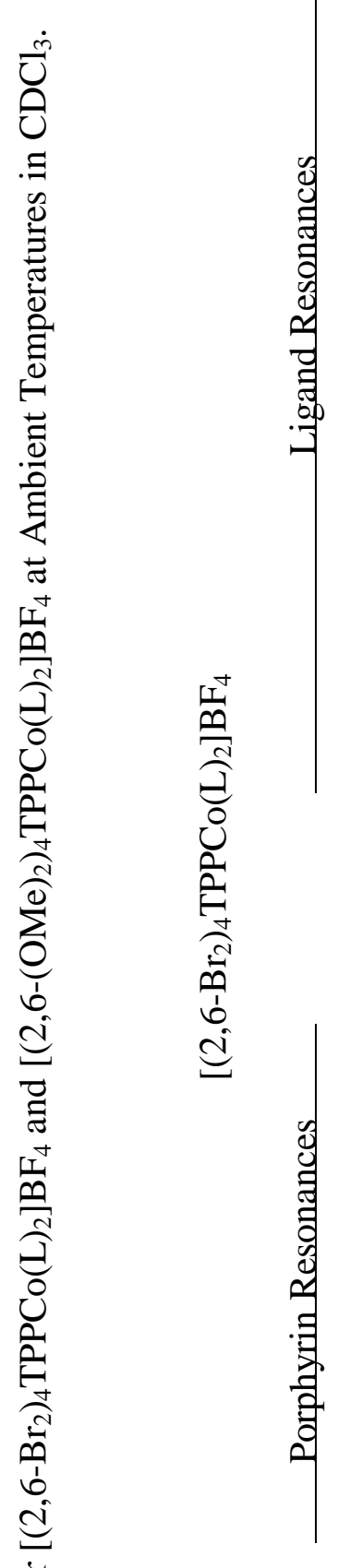

$\sum_{\substack{0 \\ 0}}^{+0}$

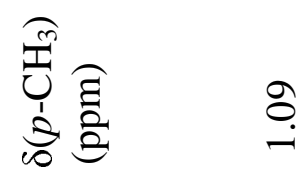

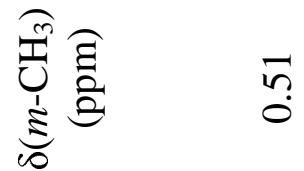

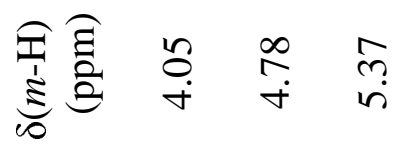

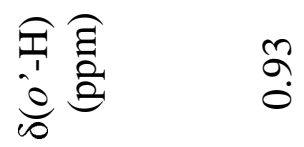

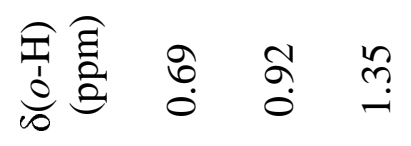

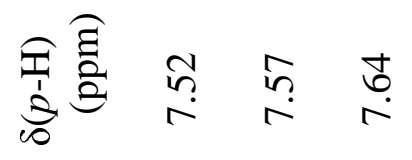

崩

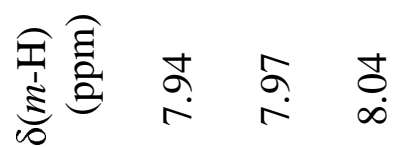

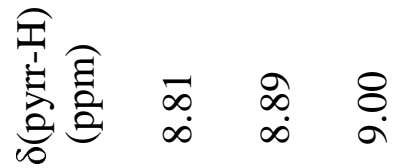

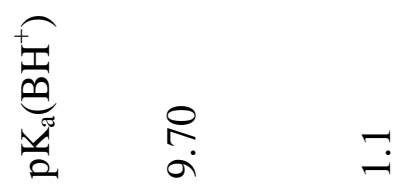

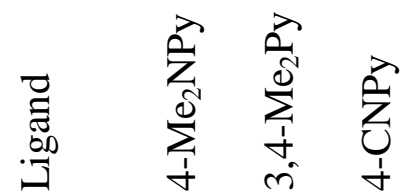

$\sum_{0}^{\infty} \frac{\pi}{n}$

焉苗

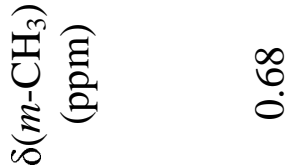

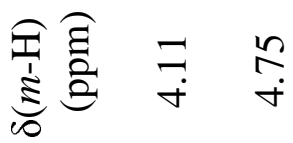

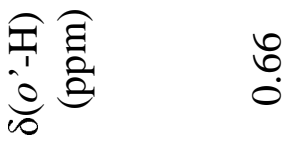

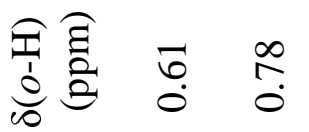

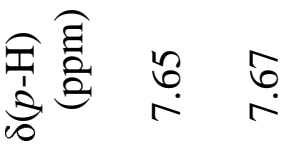

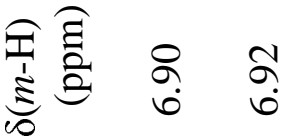

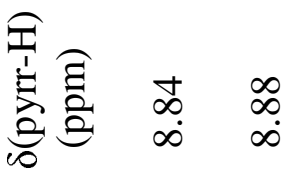

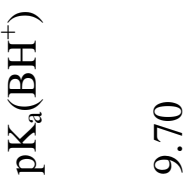

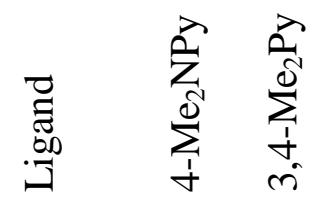


$m$

$\stackrel{\infty}{-}$

N

ఫิ

$\overbrace{\infty}^{\infty}$

$\exists$

$\sum_{\substack{1 \\ \vdots}}^{\lambda}$ 
Table S7. ${ }^{1} \mathrm{H}$ Chemical Shifts for $\left[\mathrm{TMPCo}(\mathrm{L})_{2}\right] \mathrm{BF}_{4}$ Complexes at Ambient Temperatures in $\mathrm{CDCl}_{3}{ }^{43}$

\begin{tabular}{|c|c|c|c|c|c|}
\hline Ligand & $\mathrm{pK}_{\mathrm{a}}\left(\mathrm{BH}^{+}\right)$ & $\begin{array}{c}\delta(\text { pyrr-H) } \\
(\text { ppm })\end{array}$ & $\begin{array}{r}\delta(o-\mathrm{Me}) \\
(\mathrm{ppm})\end{array}$ & $\begin{array}{r}\delta(p-\mathrm{Me}) \\
(\mathrm{ppm})\end{array}$ & $\begin{array}{r}\delta(m-\mathrm{H}) \\
(\mathrm{ppm})\end{array}$ \\
\hline $4-\mathrm{Me}_{2} \mathrm{NPy}$ & 9.70 & 8.81 & 1.50 & 2.55 & 7.21 \\
\hline $4-\mathrm{NH}_{2} \mathrm{Py}$ & 9.17 & 8.74 & 1.44 & 2.54 & 7.14 \\
\hline 2-MeHIm & 7.56 & 8.62 & $\begin{array}{l}2.75,2.60 \\
-0.04,-0.35\end{array}$ & 2.49 & $\begin{array}{l}7.42,7.36 \\
6.77,6.67\end{array}$ \\
\hline 1-MeIm & 7.33 & 8.80 & 1.55 & 2.57 & 7.21 \\
\hline 4-MeHIm & 7.12 & 8.67 & 1.42 & 2.53 & 7.11 \\
\hline HIm & 6.95 & 8.63 & 1.33 & 2.53 & 7.09 \\
\hline Py & 5.22 & 8.93 & 1.42 & 2.58 & 7.25 \\
\hline 4-ClPy & 3.75 & 8.93 & 1.47 & 2.57 & 7.22 \\
\hline 3-ClPy & 2.84 & 8.95 & 1.45 & 2.57 & 7.22 \\
\hline 3-CNPy & 1.45 & 8.95 & 1.45 & 2.57 & 7.21 \\
\hline 4-CNPy & 1.1 & 8.95 & 1.42 & 2.56 & 7.21 \\
\hline
\end{tabular}




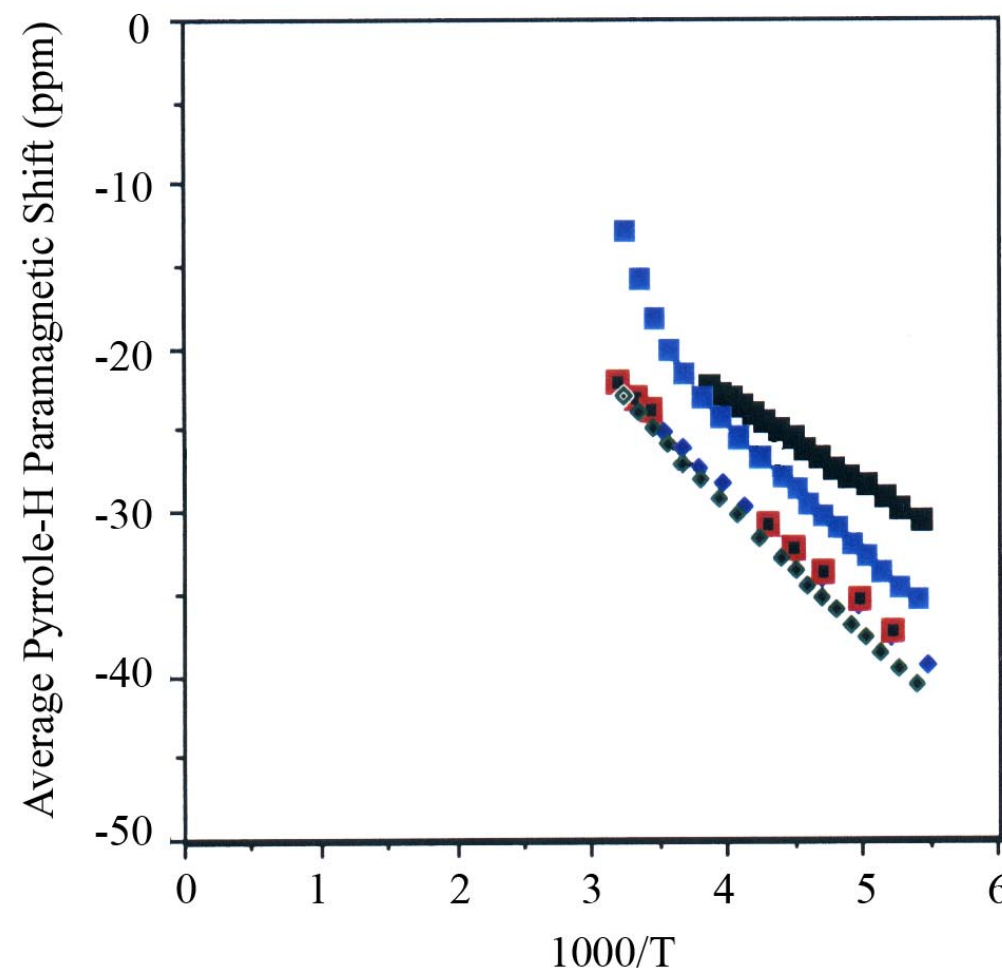

- TMP 2MeHIm avg

- Br2 2MeHIm avg

- $\mathrm{Cl} 22 \mathrm{MeHIm}$ avg

- F2 2MeHIm

- $(\mathrm{OMe}) 2 \mathrm{MeHIm}$

Figure S1. Paramagnetic shift vs. 1000/T for the pyrrole-H of the bis-2-methylimidazole complexes of the five iron(III) porphyrinates. Note the similar paramagnetic shifts and Curie behavior for all but the $\left[(2,6-(\mathrm{OMe}))_{4} \mathrm{TPPFe}(2-\mathrm{MeHIm})_{2}\right]^{+}$complex. 


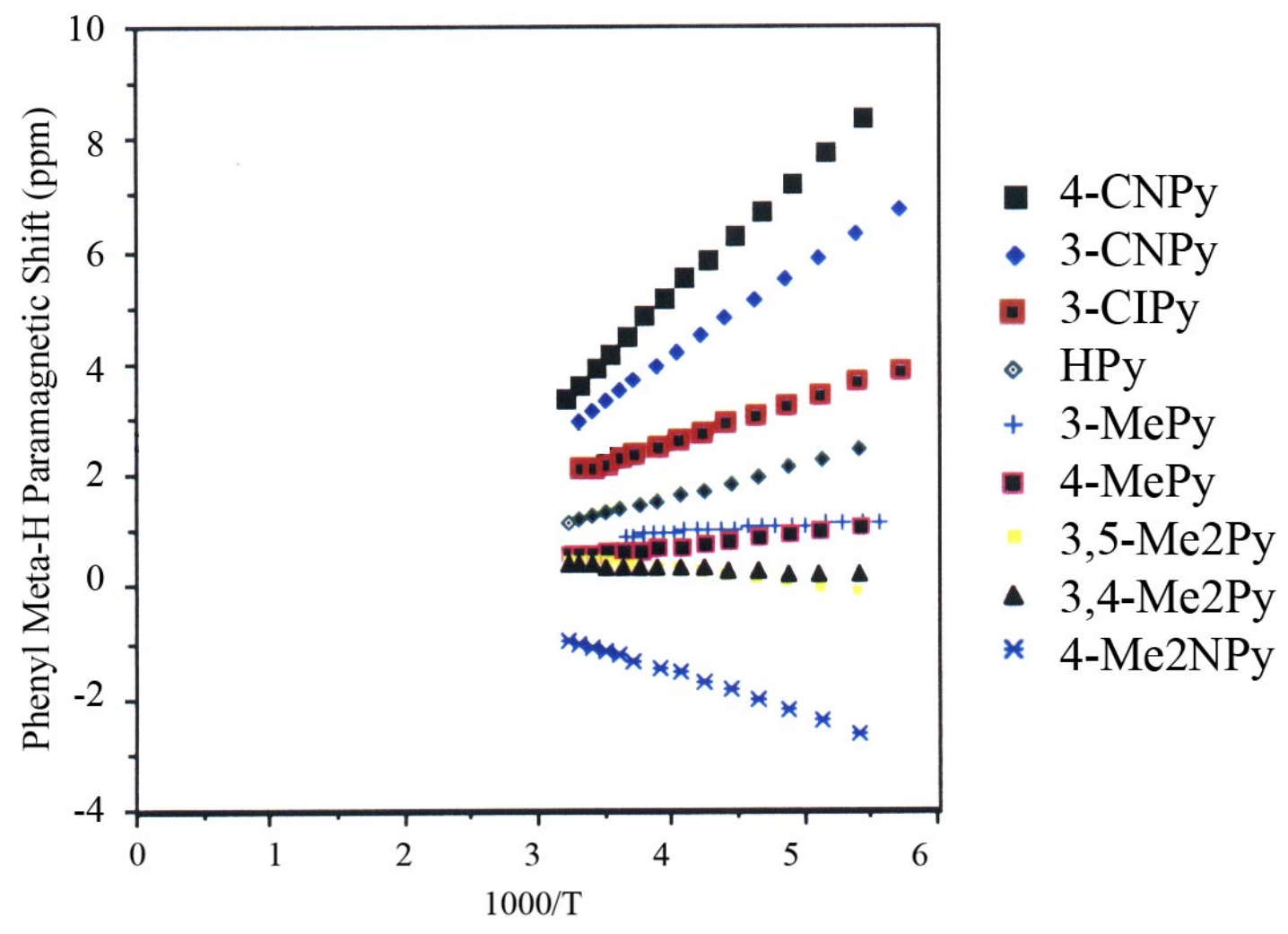

Figure S2. Paramagnetic shift vs. 1000/T plot for the $m e t a-\mathrm{H}_{\mathrm{Ph}}$ of the $\left[\mathrm{TMPFe}(\mathrm{L})_{2}\right]^{+}$complexes. 


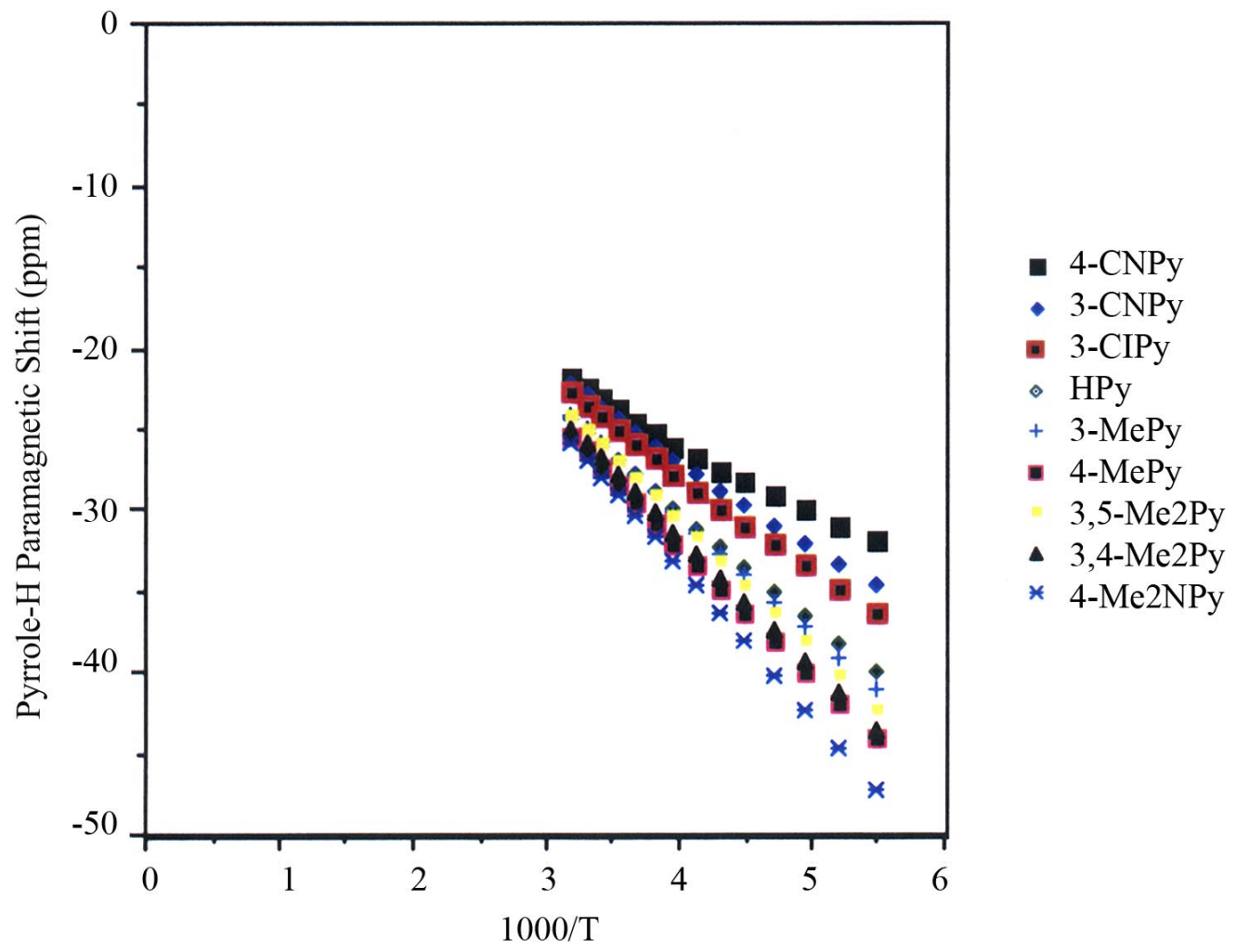

Figure S3. Paramagnetic shift vs. $1000 / \mathrm{T}$ plot for the pyrrole-H of the $\left[\left(2,6-\mathrm{Br}_{2}\right)_{4} \mathrm{TPPFe}(\mathrm{L})_{2}\right]^{+}$ complexes showing non-Curie behavior of the low-basicity pyridine complexes and Curie behavior for the high-basicity pyridine complexes. 


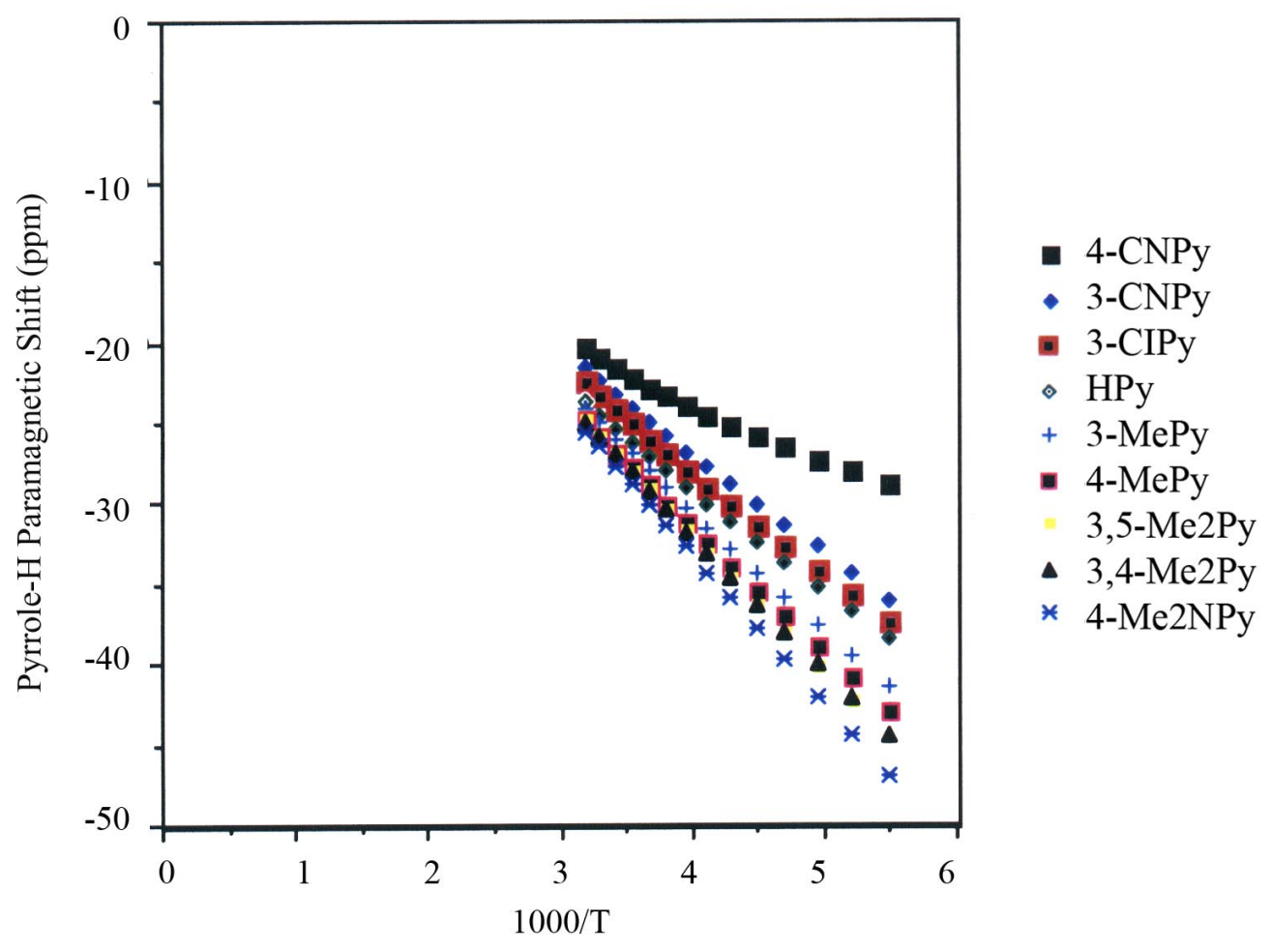

Figure S4. Paramagnetic shift vs. $1000 / \mathrm{T}$ plot for the pyrrole-H of the $\left[\left(2,6-\mathrm{Cl}_{2}\right)_{4} \mathrm{TPPFe}(\mathrm{L})_{2}\right]^{+}$ complexes. Note that these plots are nearly identical to those of $\left[\left(2,6-\mathrm{Br}_{2}\right)_{4} \mathrm{TPPFe}(\mathrm{L})_{2}\right]^{+}$shown in Figure S3. 


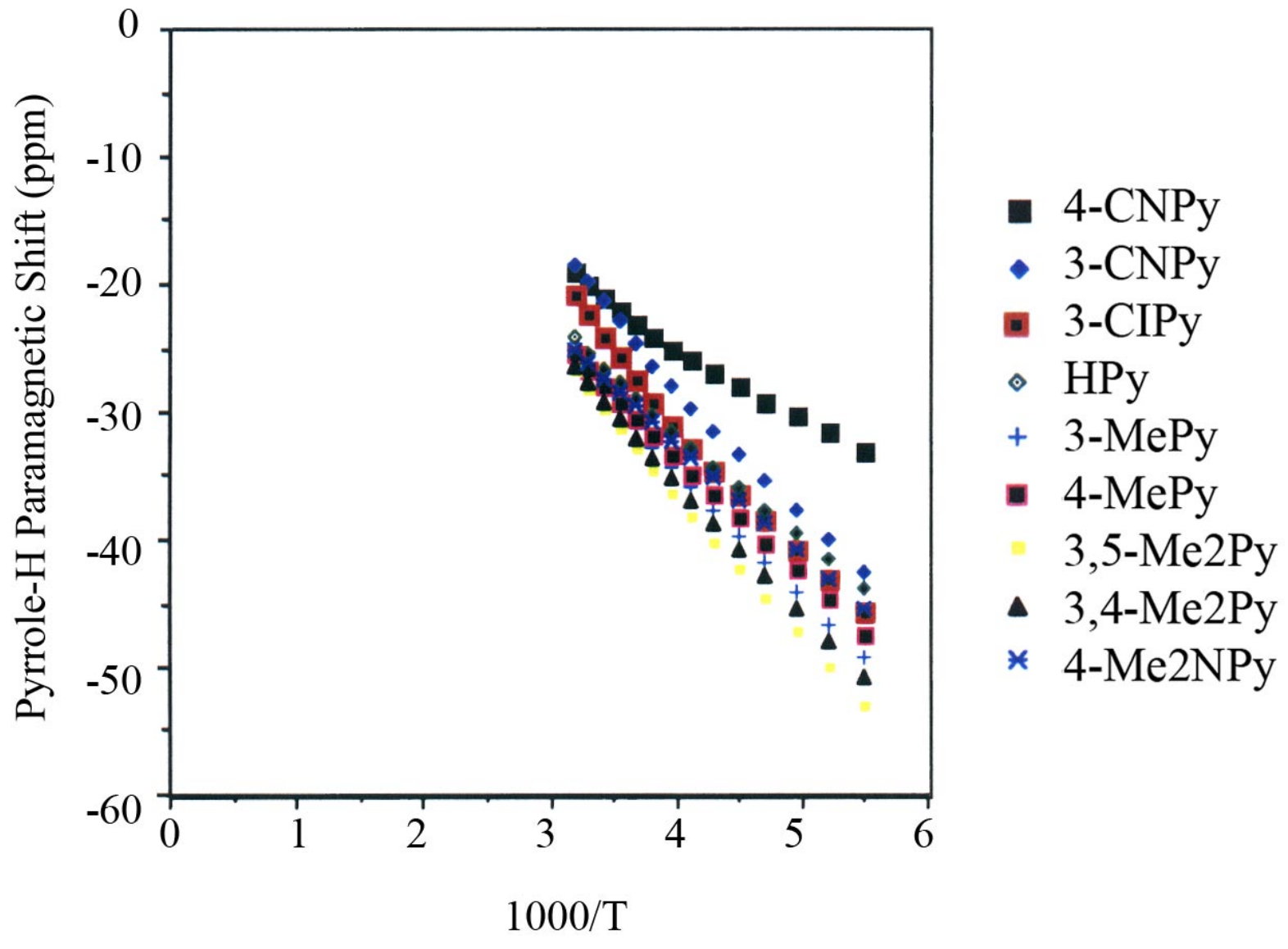

Figure S5. Paramagnetic shift vs. 1000/T plot for the pyrrole-H of the $\left[\left(2,6-\mathrm{F}_{2}\right)_{4} \mathrm{TPPFe}(\mathrm{L})_{2}\right]^{+}$ complexes. Note the separation of the 4-CNPy line from those of the other complexes. 


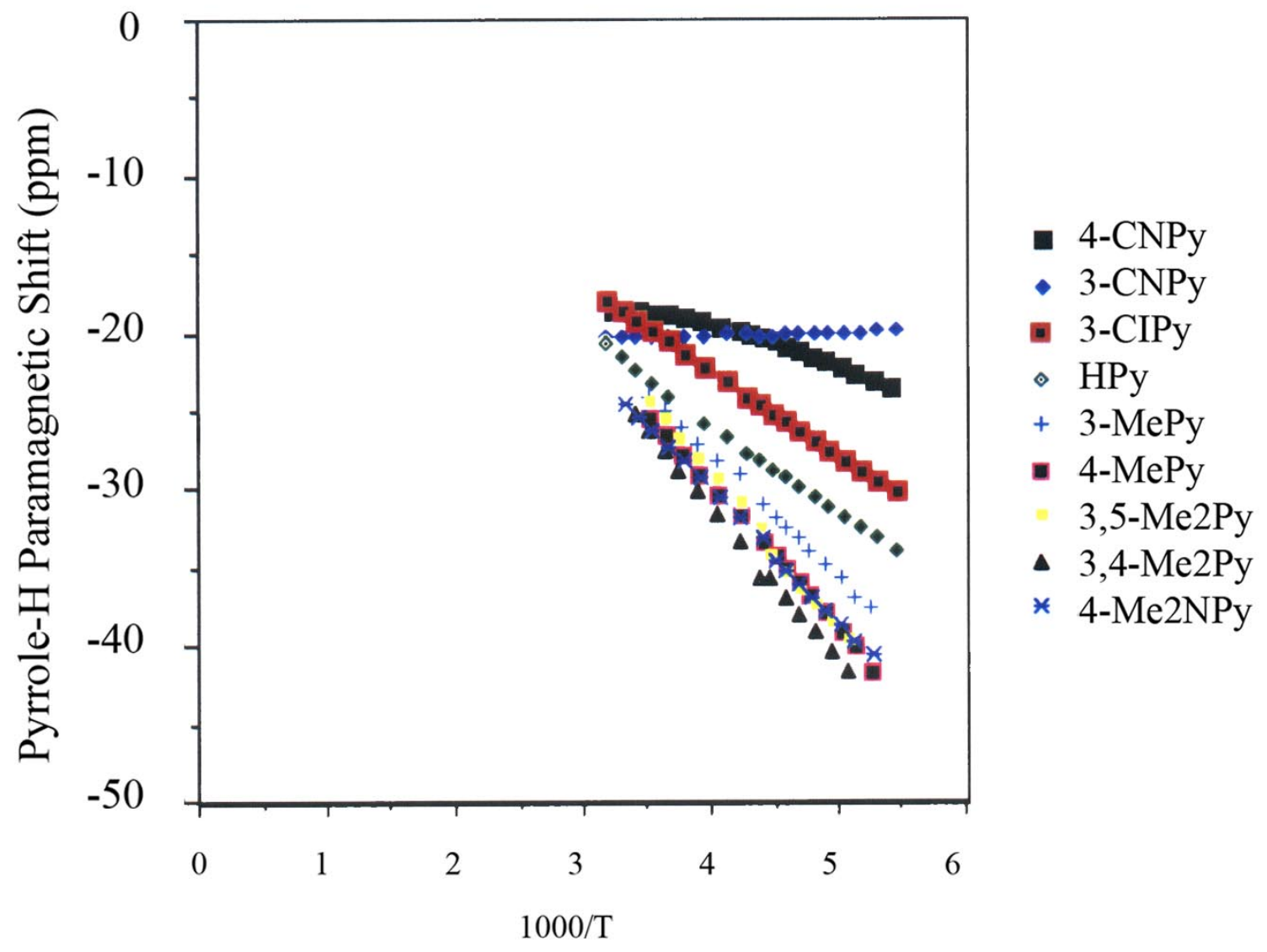

Figure S6. Paramagnetic shift vs. 1000/T for the pyrrole-H of the $\left[\left(2,6-(\mathrm{OMe})_{2}\right)_{4} \mathrm{TPPFe}(\mathrm{L})_{2}\right]^{+}$ complexes. Note the odd curvature of the 4-CNPy line and the very little temperature dependence of the 3-CNPy plot. 


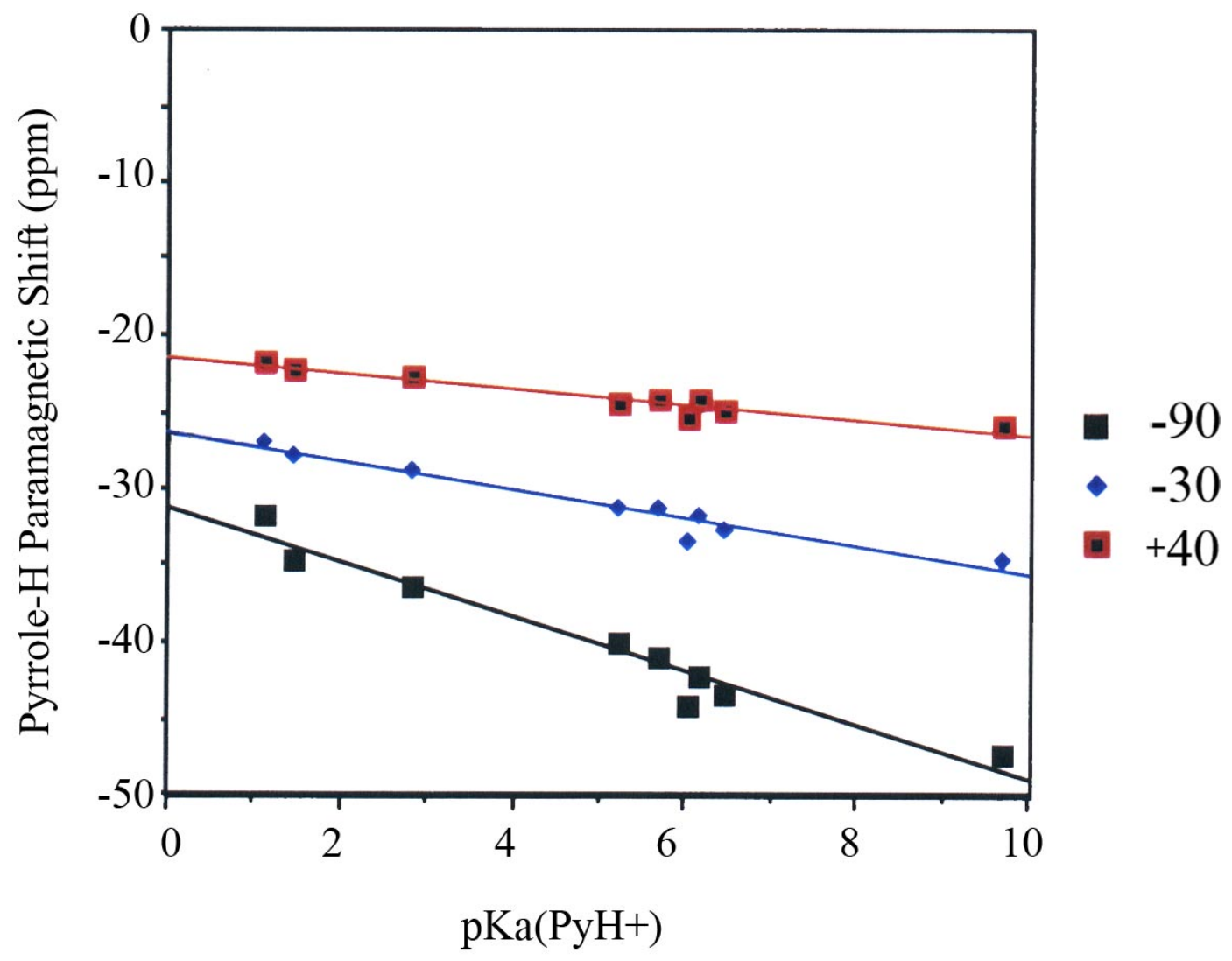

Figure S7. Paramagnetic shift vs. $\mathrm{pK}_{\mathrm{a}}\left(\mathrm{PyH}^{+}\right)$plot for the pyrrole-H of the $\left[\left(2,6-\mathrm{Br}_{2}\right)_{4} \mathrm{TPPFe}(\mathrm{L})_{2}\right]^{+}$ complexes at $-90,-30$, and $+40{ }^{\circ} \mathrm{C}$. Note the less drastic change in slope with temperature as compared to the $\left[\mathrm{TMPFe}(\mathrm{L})_{2}\right]^{+}$plot (Figure 2). 


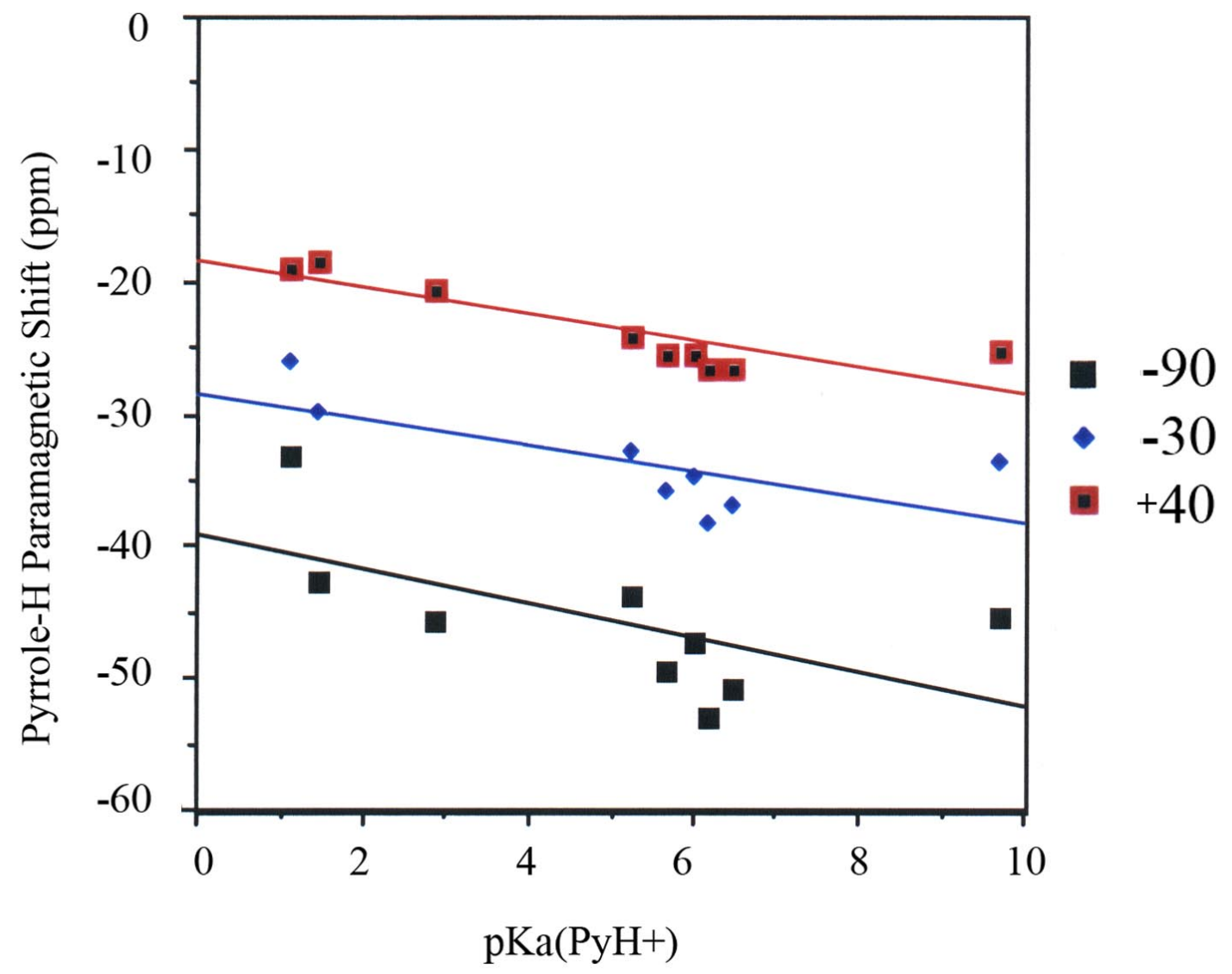

Figure S8. Paramagnetic shift vs. $\mathrm{pK}_{\mathrm{a}}\left(\mathrm{PyH}^{+}\right)$plot for the pyrrole- $\mathrm{H}$ of the $\left[\left(2,6-\mathrm{F}_{2}\right)_{4}-\mathrm{TPPFe}(\mathrm{L})_{2}\right]^{+}$ complexes at $-90,-30$, and $+40{ }^{\circ} \mathrm{C}$. Note that there is very little change in slope with temperature. 


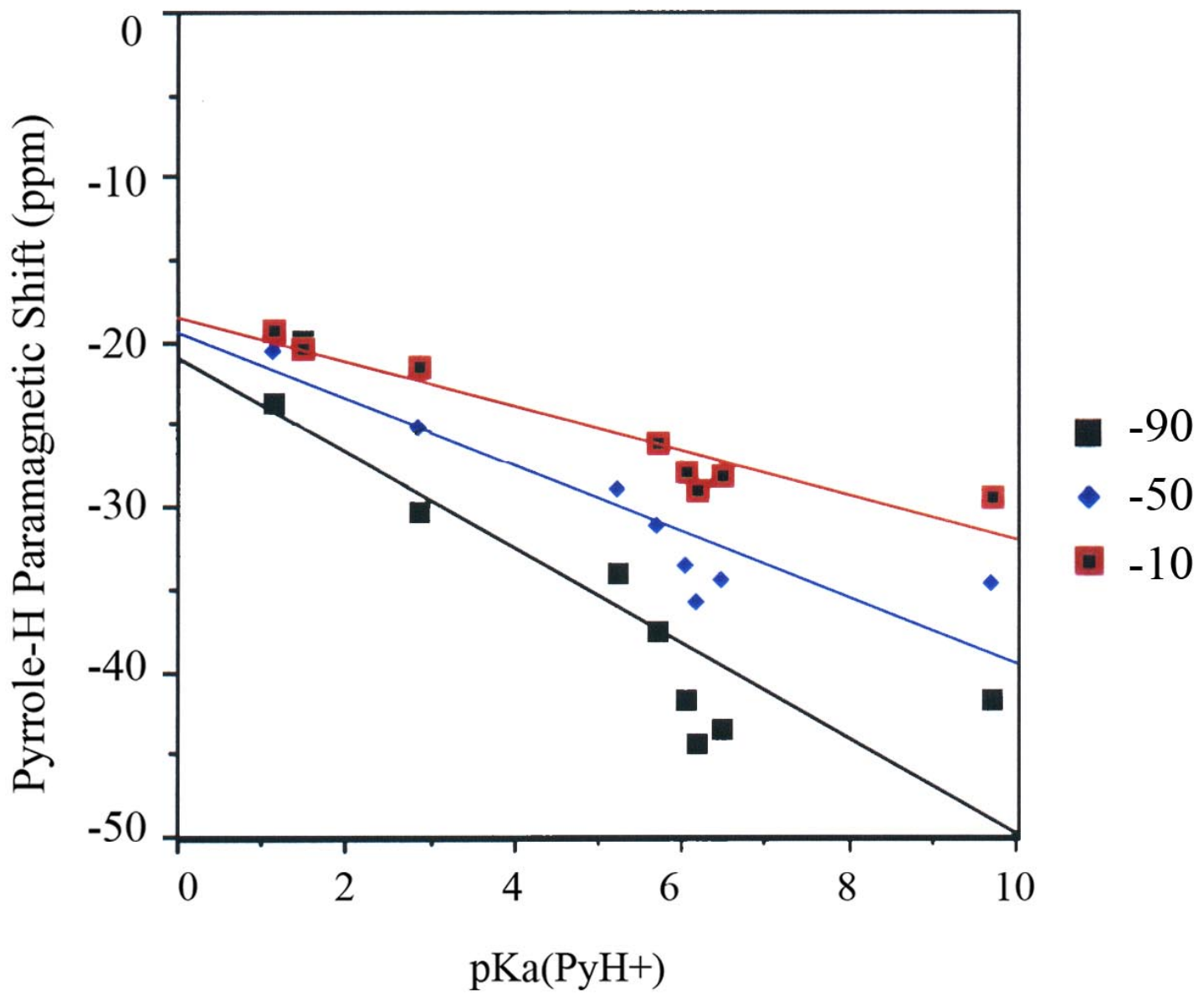

Figure S9. Paramagnetic shift vs. $\mathrm{pK}_{\mathrm{a}}\left(\mathrm{PyH}^{+}\right)$for the pyrrole- $\mathrm{H}$ of the $\left[\left(2,6-(\mathrm{OMe})_{2}\right)_{4} \mathrm{TPPFe}(\mathrm{L})_{2}\right]^{+}$ complexes at $-90,-50$, and $-10{ }^{\circ} \mathrm{C}$. 


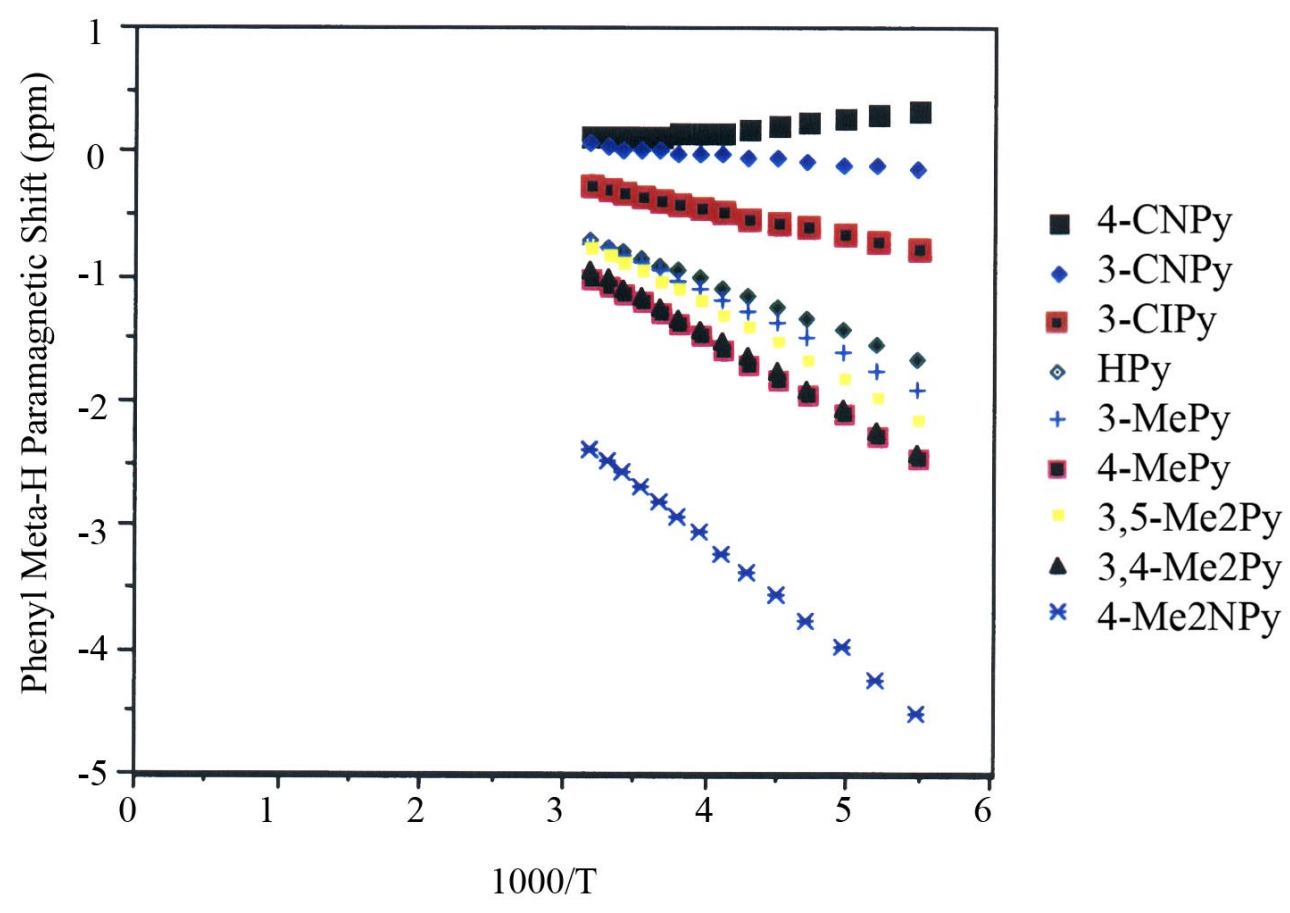

Figure S10. Paramagnetic shifts vs. $1000 / \mathrm{T}$ for the $m-\mathrm{H}_{\mathrm{Ph}}$ of the $\left[\left(2,6-\mathrm{Br}_{2}\right)_{4} \mathrm{TPPFe}(\mathrm{L})_{2}\right]^{+}$complexes showing near-Curie behavior for all but the 4-CNPy complex. 


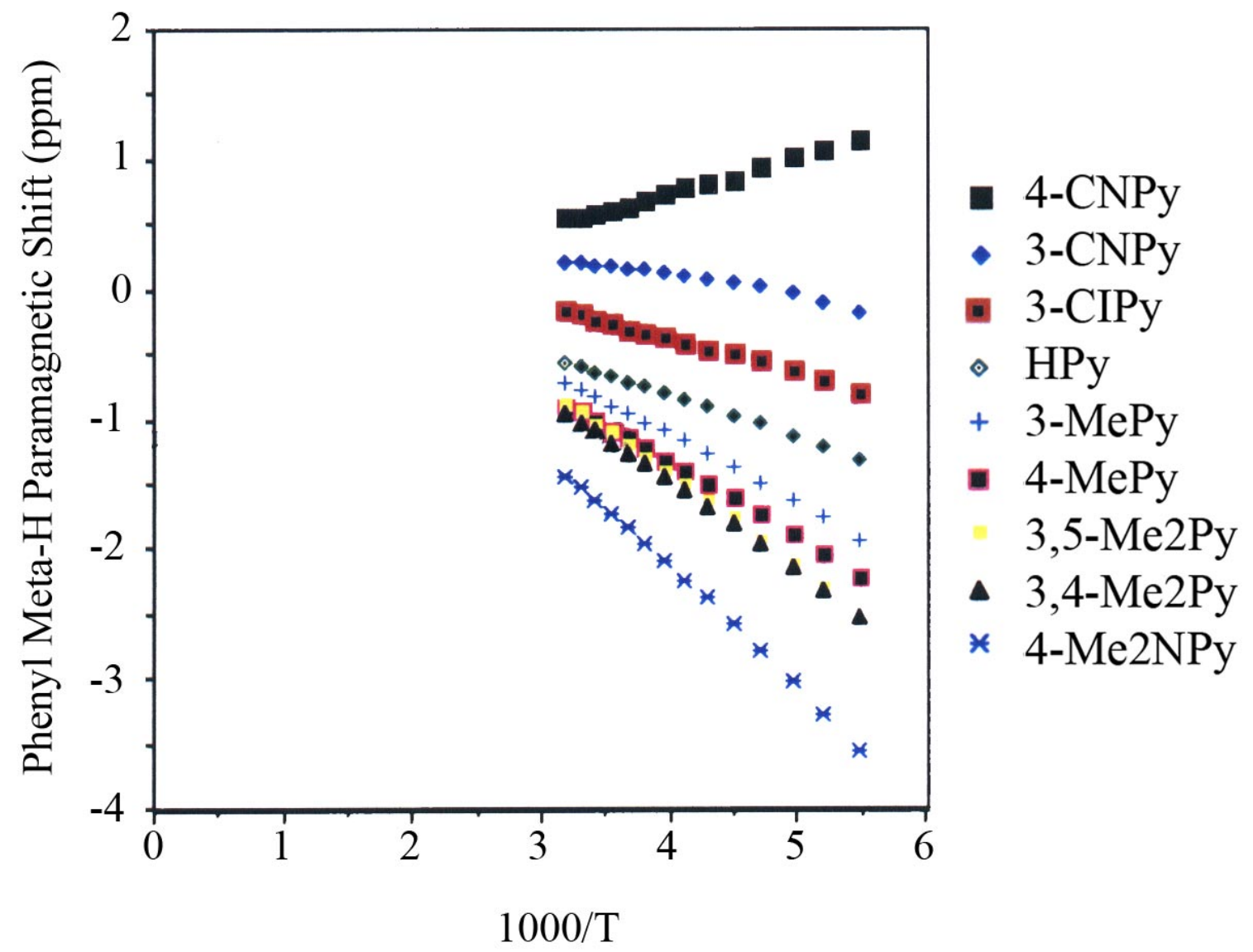

Figure S11. Paramagnetic shift vs. $1000 / \mathrm{T}$ plot for the $m-\mathrm{H}_{\mathrm{Ph}}$ resonances of the $[(2,6-$

$\left.\left.\mathrm{Cl}_{2}\right)_{4} \mathrm{TPPFe}(\mathrm{L})_{2}\right]^{+}$complexes showing near-Curie behavior for all but the 4-CNPy complex. 


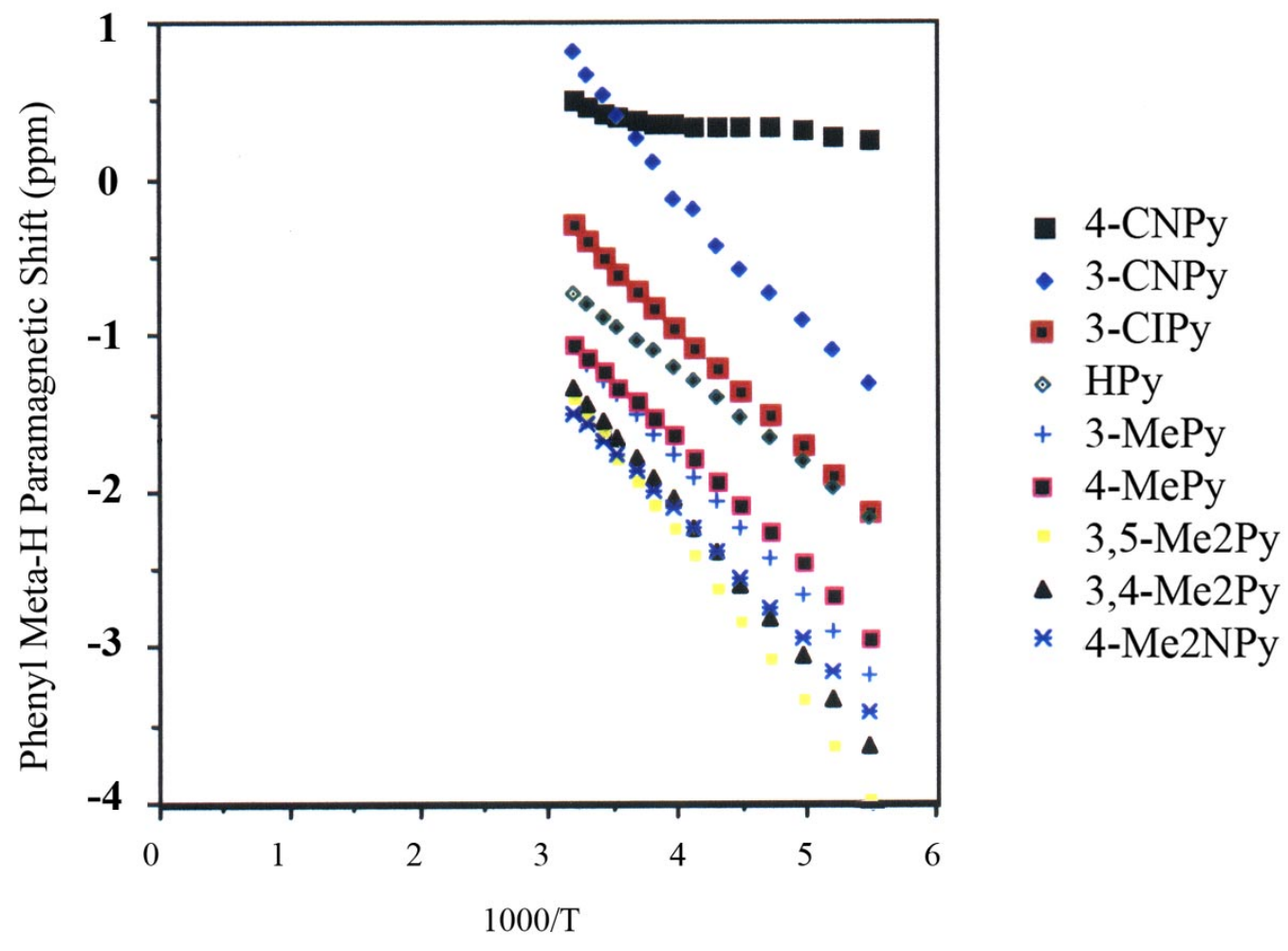

Figure S12. Paramagnetic shift vs. $1000 / \mathrm{T}$ of the $m-\mathrm{H}_{\mathrm{Ph}}$ resonances of the $\left[\left(2,6-\mathrm{F}_{2}\right)_{4} \mathrm{TPPFe}(\mathrm{L})_{2}\right]^{+}$ complexes showing the same crossing of the 4-CNPy and 3-CNPy shifts as seen in the pyrrole-H shifts in Figure S8. 


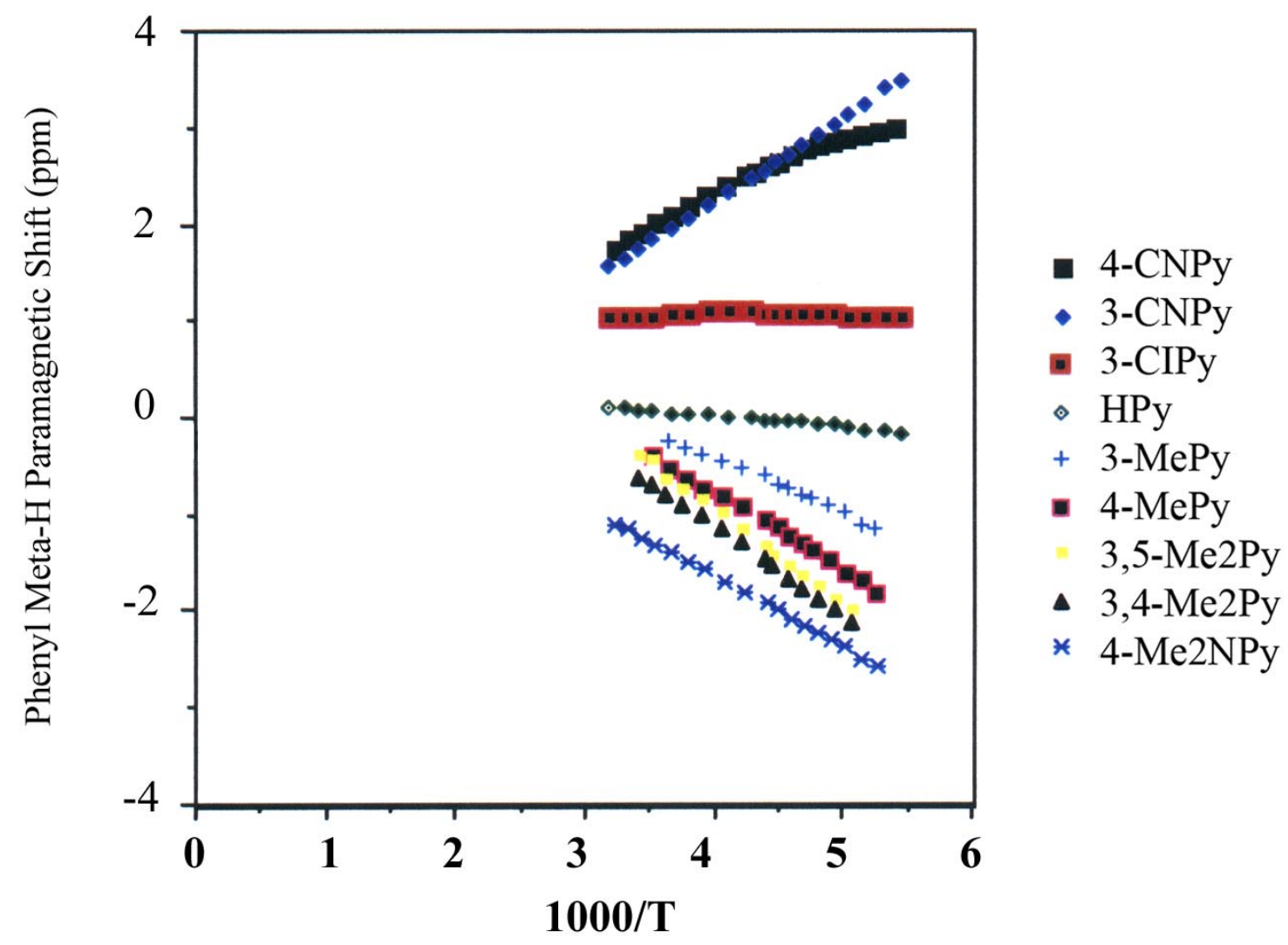

Figure S13. Paramagnetic shift vs. $1000 / \mathrm{T}$ for the $m-\mathrm{H}_{\mathrm{Ph}}$ resonances of the $[(2,6-$

$\left.\left.(\mathrm{OMe})_{2}\right)_{4} \mathrm{TPPFe}(\mathrm{L})_{2}\right]^{+}$complexes showing the same linear, non-Curie behavior for the 3-CNPy shifts seen in the pyrrole-H shifts. 


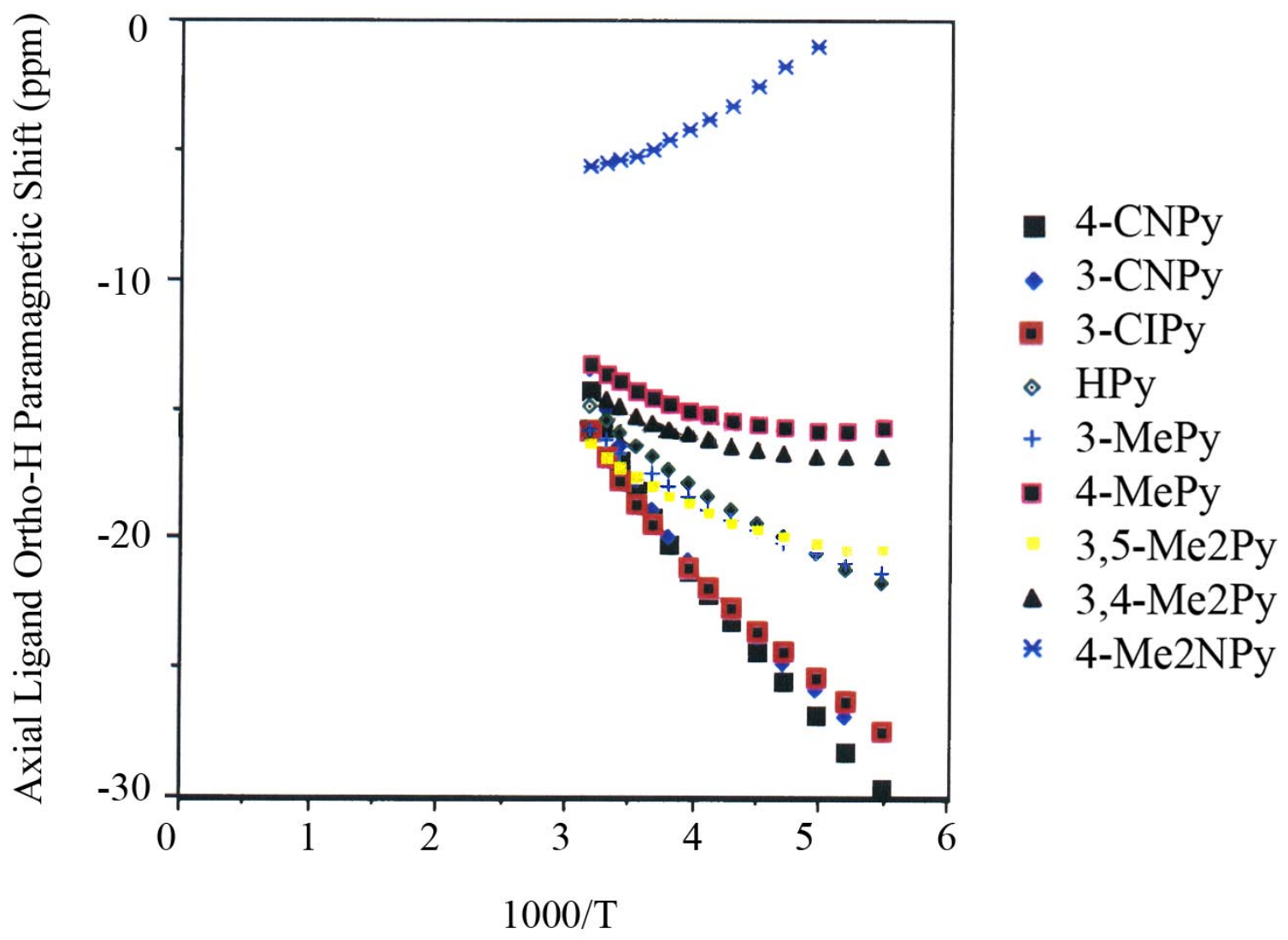

Figure S14. Paramagnetic shift vs. $1000 / \mathrm{T}$ plot for the $o-\mathrm{H}_{\mathrm{Py}}$ of the $\left[\left(2,6-\mathrm{Br}_{2}\right)_{4} \mathrm{TPPFe}(\mathrm{L})_{2}\right]^{+}$complexes showing the reversed ordering as compared to the pyrrole-H paramagnetic shifts. 


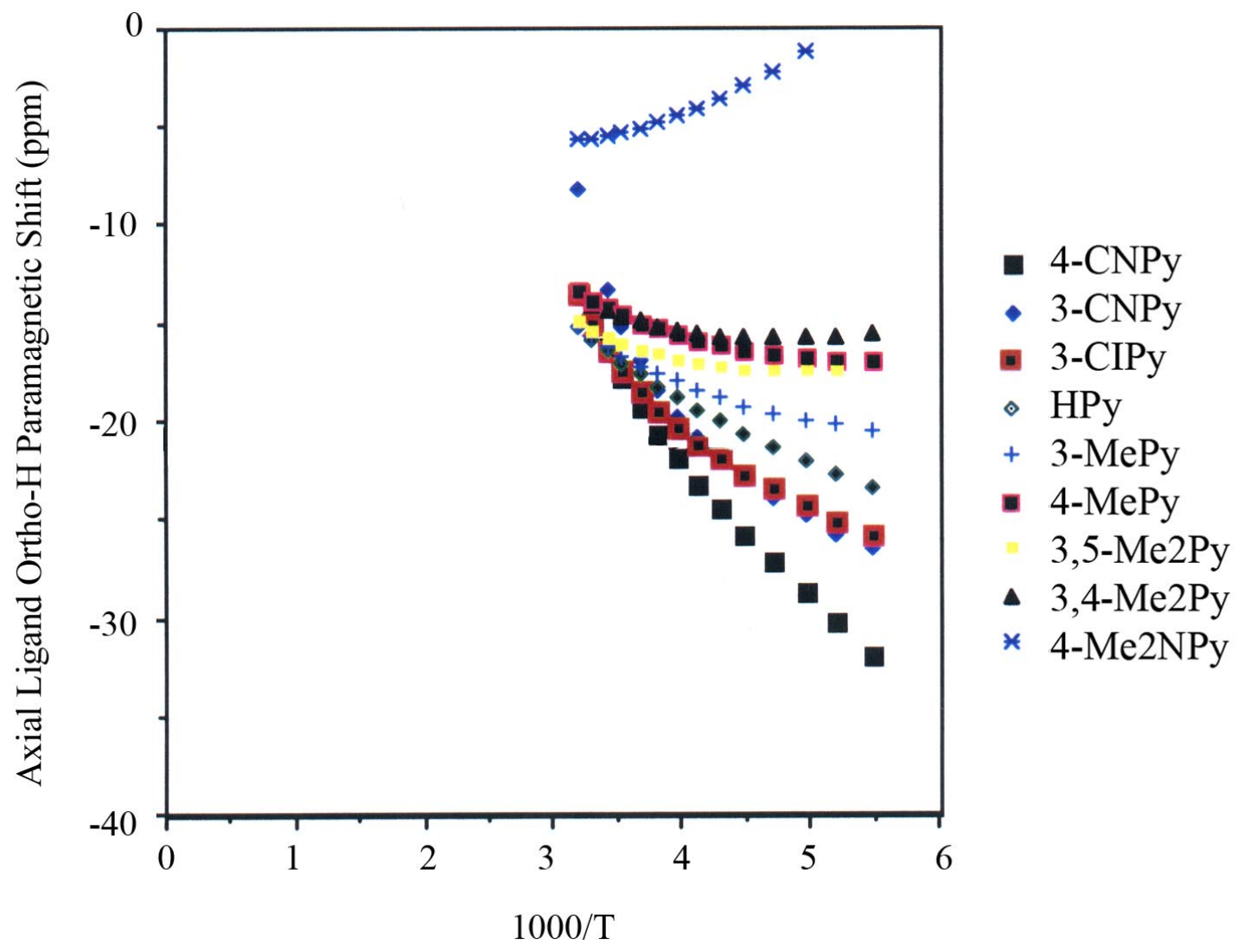

Figure S15. Paramagnetic shift vs. $1000 / \mathrm{T}$ plot for the $o-\mathrm{H}_{\mathrm{Py}}$ of the $\left[\left(2,6-\mathrm{Cl}_{2}\right)_{4} \mathrm{TPPFe}(\mathrm{L})_{2}\right]^{+}$complexes showing the reversed ordering as compared to the pyrrole- $\mathrm{H}$ paramagnetic shifts. 


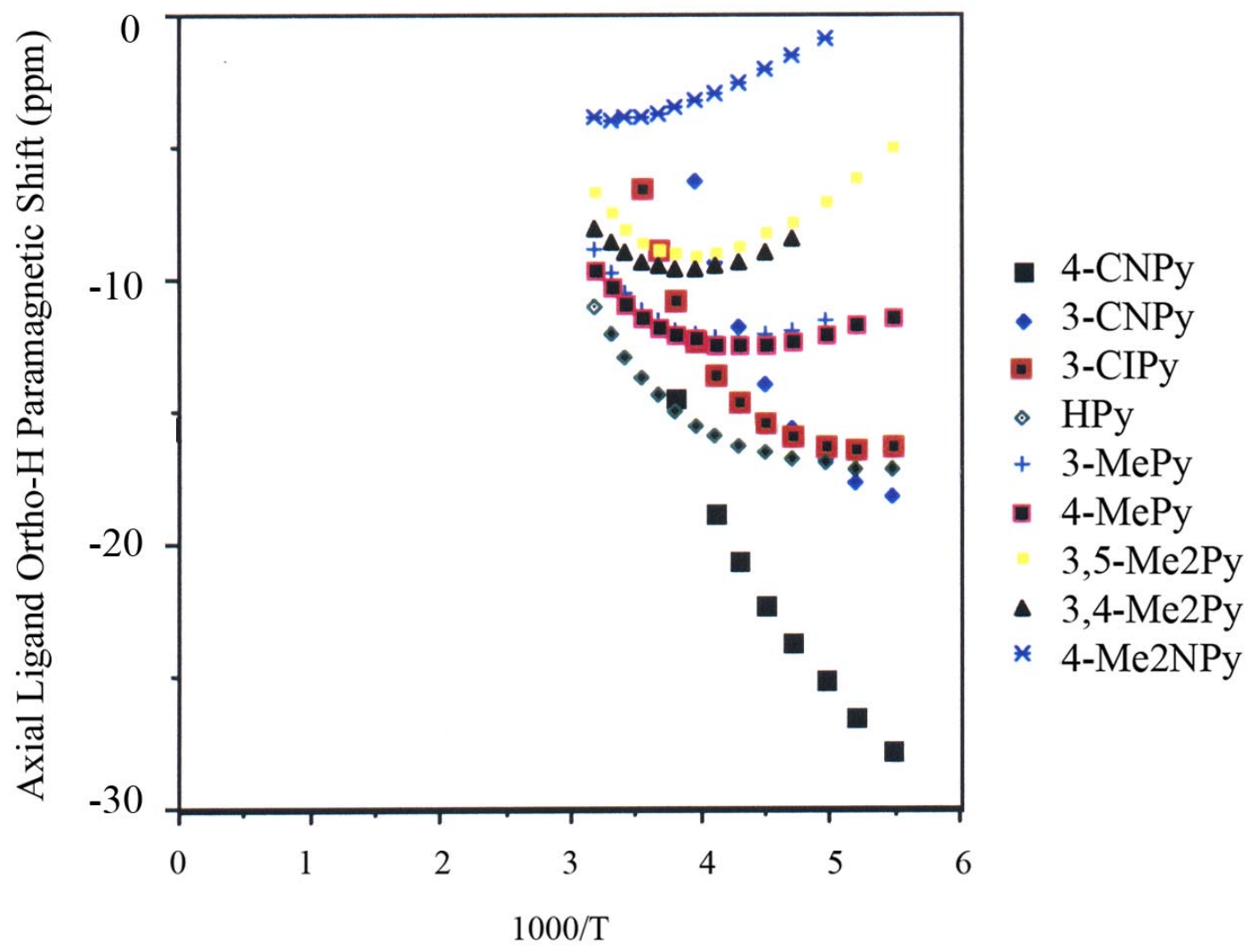

Figure S16. Paramagnetic shift vs. $1000 / \mathrm{T}$ graph for the $o-\mathrm{H}_{\mathrm{Py}}$ of the $\left[\left(2,6-\mathrm{F}_{2}\right)_{4} \mathrm{TPPFe}(\mathrm{L})_{2}\right]^{+}$ complexes. Note that the lower-basicity pyridine lines shift to more positive paramagnetic shift values more rapidly with increasing temperature than do the higher-basicity pyridines. 


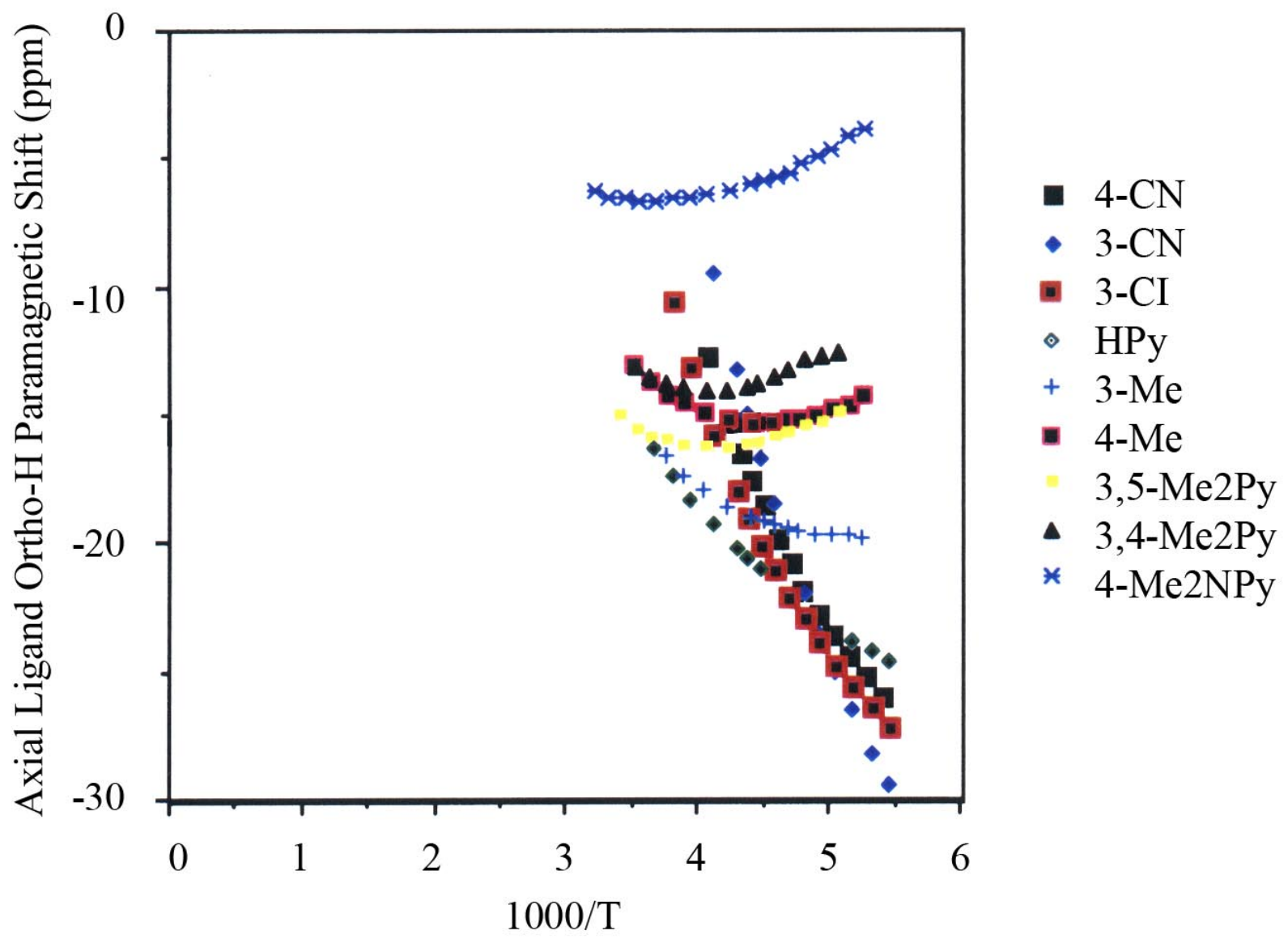

Figure S17. Paramagnetic shift vs. $1000 / \mathrm{T}$ plot for the $o-\mathrm{H}_{\mathrm{Py}}$ of the $\left[\left(2,6-(\mathrm{OMe})_{2}\right)_{4} \mathrm{TPPFe}(\mathrm{L})_{2}\right]^{+}$ complexes. Note the extremely negative slopes of the lower basicity pyridine shifts. 


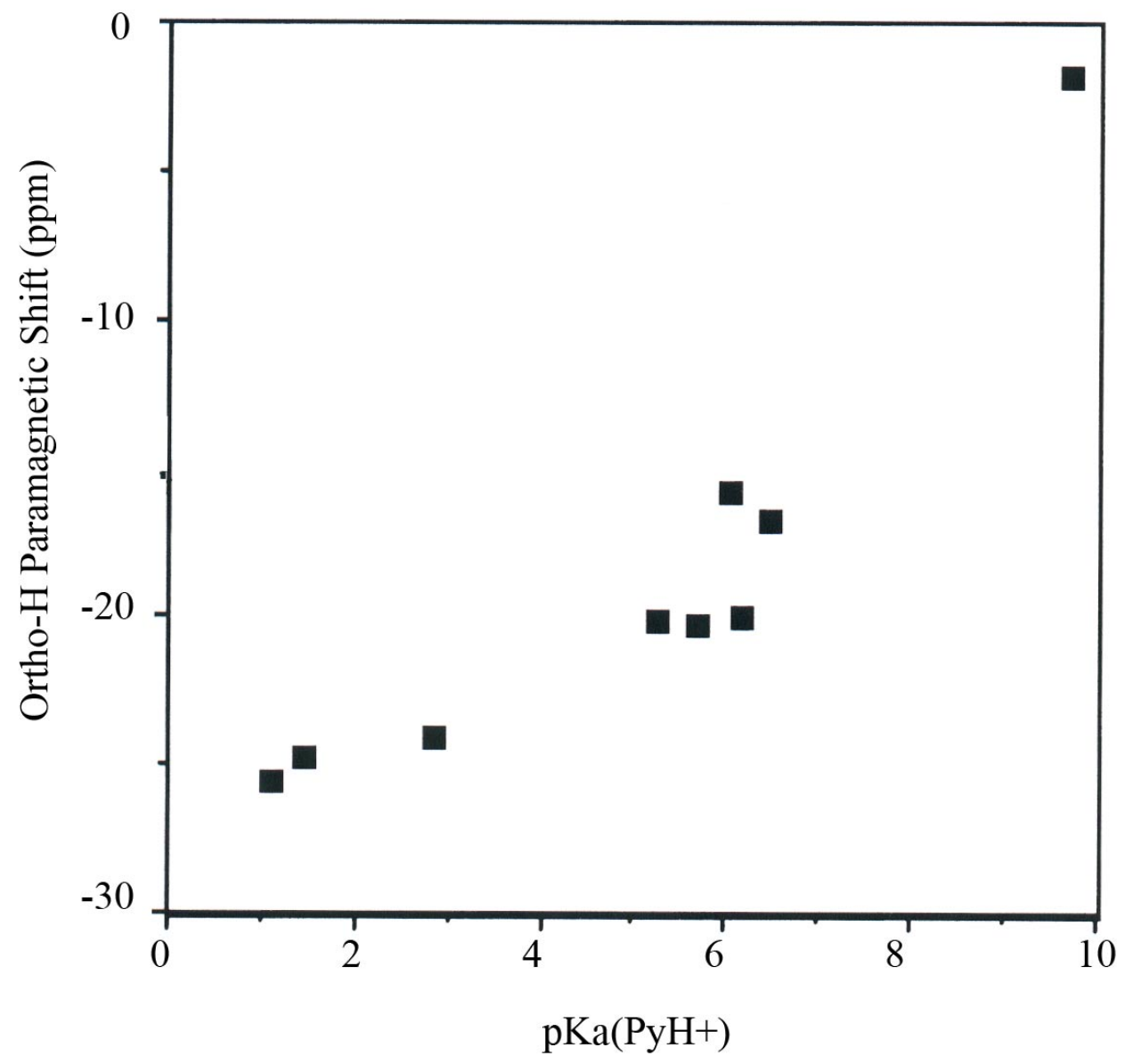

Figure S18. Paramagnetic shift of the $o-\mathrm{H}_{\mathrm{Py}}$ resonances at $-60{ }^{\circ} \mathrm{C}$ vs. $\mathrm{pK}_{\mathrm{a}}\left(\mathrm{PyH}^{+}\right)$for the $[(2,6-$ $\left.\left.\mathrm{Br}_{2}\right)_{4} \mathrm{TPPFe}(\mathrm{L})_{2}\right]^{+}$complexes showing that the break in the line at a $\mathrm{pK}_{\mathrm{a}}$ near 5 is less apparent compared with the $\left[\mathrm{TMPFe}(\mathrm{L})_{2}\right]^{+}$plot shown in Figure 5. 


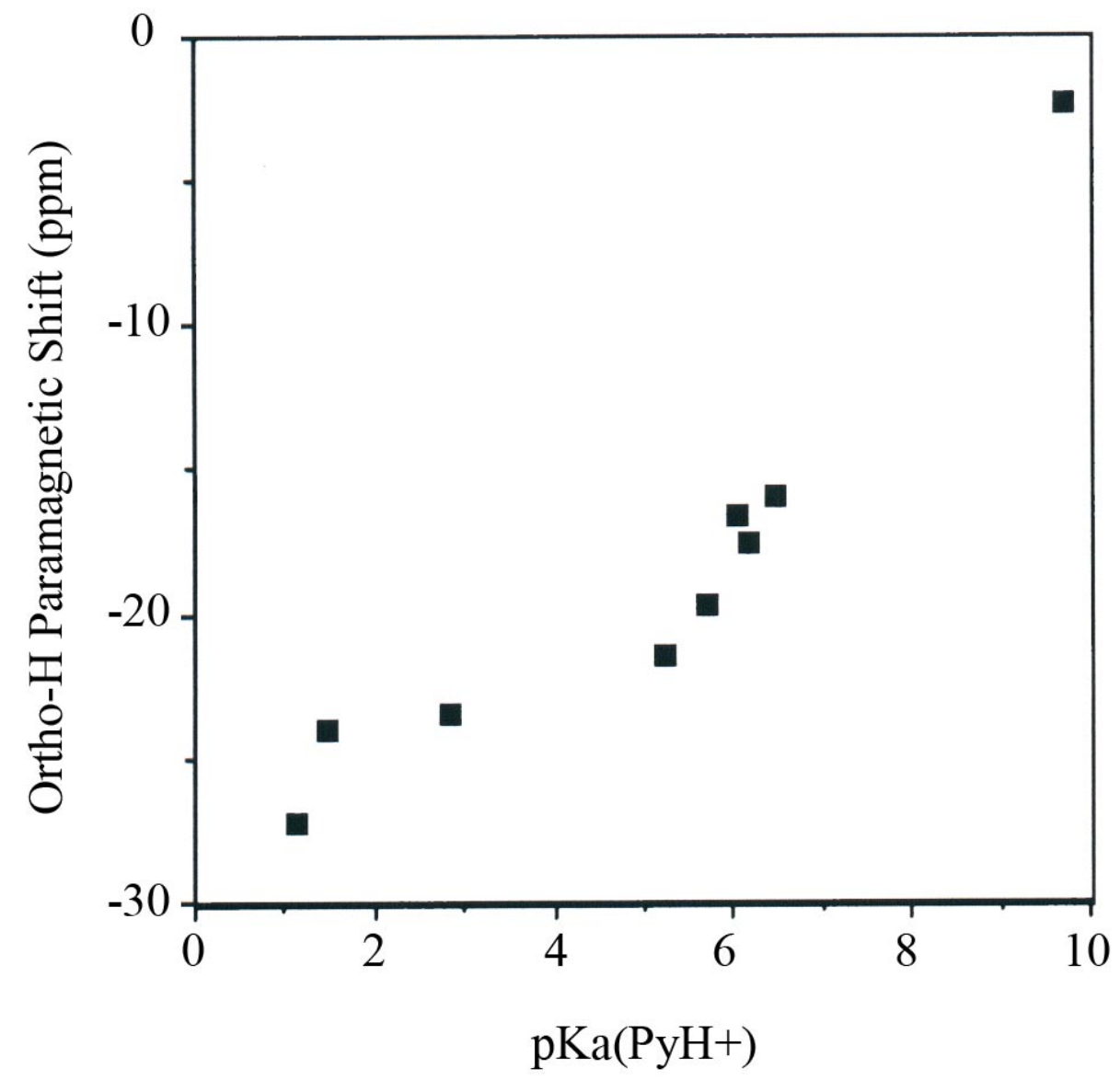

Figure S19. Paramagnetic shift of the $o-\mathrm{H}_{\mathrm{Py}}$ resonances at $-60{ }^{0} \mathrm{C}$ vs. $\mathrm{pK}_{\mathrm{a}}\left(\mathrm{PyH}^{+}\right)$for the $[(2,6-$ $\left.\left.\mathrm{Cl}_{2}\right)_{4} \mathrm{TPPFe}(\mathrm{L})_{2}\right]^{+}$complexes showing that the apparent break in the line at a $\mathrm{pK}_{\mathrm{a}}$ near 5 is very similar to that for $\left[\left(2,6-\mathrm{Br}_{2}\right)_{4} \mathrm{TPPFe}(\mathrm{L})_{2}\right]^{+}$. 


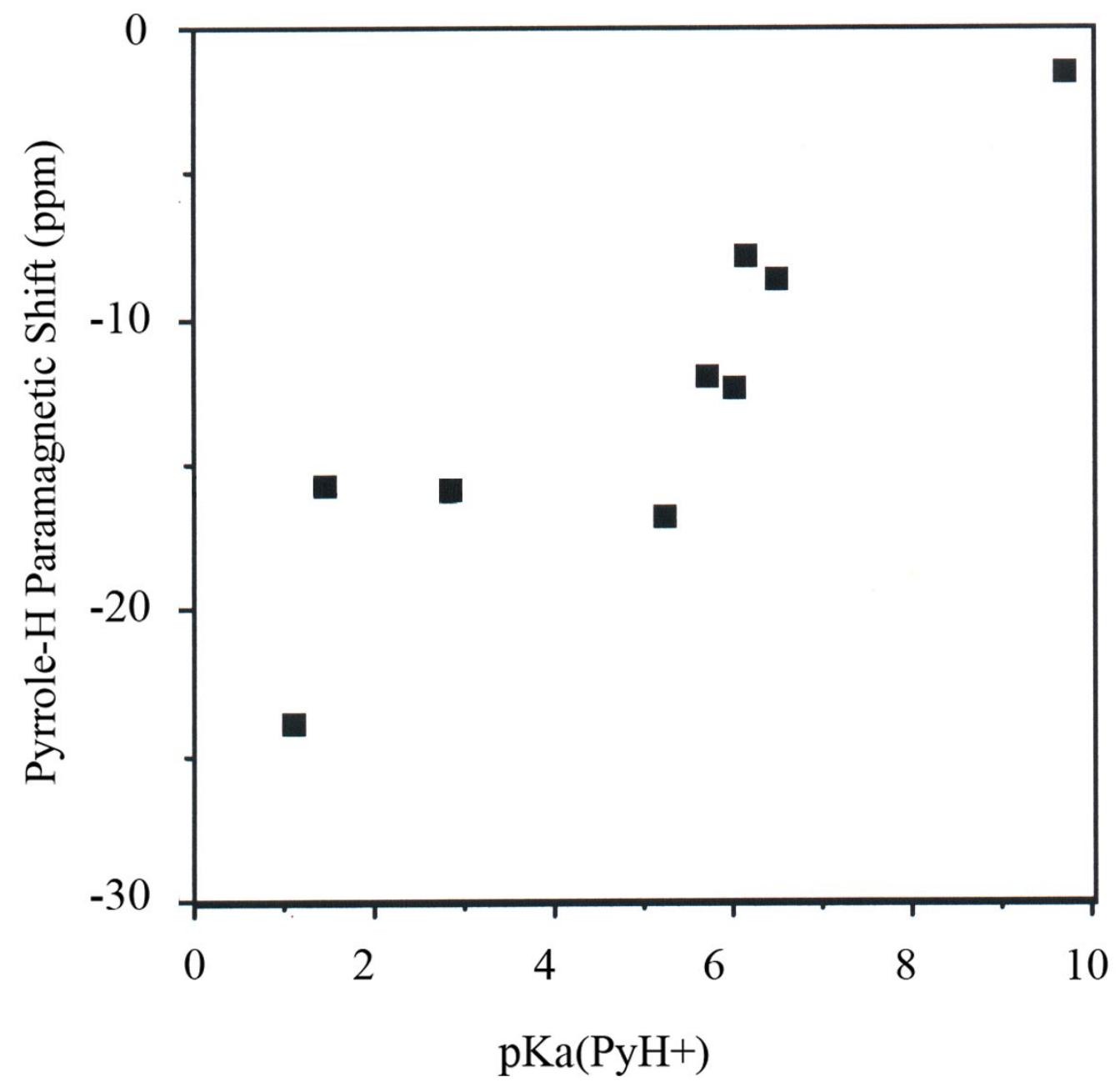

Figure S20. Paramagnetic shifts of the $o-\mathrm{H}_{\mathrm{Py}}$ resonances at $-60{ }^{\circ} \mathrm{C}$ vs. $\mathrm{pK}_{\mathrm{a}}\left(\mathrm{PyH}^{+}\right)$for the $[(2,6-$ $\left.\left.\mathrm{F}_{2}\right)_{4} \mathrm{TPPFe}(\mathrm{L})_{2}\right]^{+}$complexes, showing no apparent break in a best fit line. 
Detailed Separation of the Contact and Pseudocontact Shifts for $\left[\mathrm{TMPFe}(\mathrm{L})_{2}\right] \mathrm{ClO}_{4}$. The ability to separate the contact and pseudocontact shifts of a series of related metalloporphyrinate complexes is an obvious sign that the magnetic properties of the systems of interest are clearly understood. In the present study, the TMP complexes are the only ones that permitted this separation with any degree of confidence.

The change in magnetic anisotropy at close to the $\mathrm{pK}_{\mathrm{a}}$ of the conjugate acid of pyridine or 4methylpyridine can be used to separate the pseudocontact contribution from the contact contribution to the paramagnetic shift. But first, an assumption must be made. This assumption is that 4dimethyaminopyridine is a "pseudo-imidazole." That is, it behaves very much like an imidazole in this and other iron(III) porphyrinate complexes, and thus [TMPFe(4-Me $\left.2 \mathrm{NPy})_{2}\right]^{+}$appears to have a pure $\left(\mathrm{d}_{\mathrm{xy}}\right)^{2}\left(\mathrm{~d}_{\mathrm{xz}}, \mathrm{d}_{\mathrm{yz}}\right)^{3}$ ground state. The comparison of the temperature dependence of the pyrrole- $\mathrm{H}$ and $m-\mathrm{H}_{\mathrm{Ph}}$ resonances of [TMPFe $\left.(1-\mathrm{MeIm})_{2}\right]^{+}$and $\left[\mathrm{TMPFe}\left(4-\mathrm{Me}_{2} \mathrm{NPy}\right)_{2}\right]^{+}$in Figure 8 and the similarity of the values of $\rho_{\mathrm{C}}$ for the $\beta$-pyrrole carbon for the two complexes (Table 2) suggest that this assumption is valid. Thus, it can be seen that with the unpaired electron in the $d_{x z}, d_{y z}$ orbital set, the proper symmetry exists for spin delocalization from the $3 e(\pi)$ porphyrin orbitals by porphyrin-to-iron electron donation into the hole in $\mathrm{d}_{\mathrm{xz}}, \mathrm{d}_{\mathrm{yz}}$. For the $3 e(\pi)$ molecular orbitals the coefficients at the meso positions are zero. ${ }^{6,16}$ It can then be assumed that for the $m-\mathrm{H}_{\mathrm{Ph}}$ the paramagnetic shift due to the contact contribution is also zero. Thus, any shift away from the diamagnetic position of $7.21 \mathrm{ppm}$ (Table S7) would be due to the pseudocontact contribution. ${ }^{16,57}$ For $\left[\mathrm{TMPFe}\left(4-\mathrm{Me}_{2} \mathrm{NPy}\right)_{2}\right]^{+}$the $m-\mathrm{H}_{\mathrm{Ph}}$ resonance at $-60{ }^{\circ} \mathrm{C}$ is at $5.20 \mathrm{ppm}$; thus $\delta_{\text {para }}=\delta_{\mathrm{pc}}=-2.01 \mathrm{ppm}$.

Equation (6) shows that for different proton positions in the same molecule the differences in their pseudocontact shifts are due to their distance (r) from the metal center and angular $(\theta, \varphi)$ positions. Therefore, the ratio of their geometric factors, $\left(3 \cos ^{2} \theta-1\right) / \mathrm{r}^{3}$, Equation (6), can be used to 
calculate the pseudocontact shift of any proton in the molecule as long as there is one resonance for which the pseudocontact shift is known. La Mar et al. ${ }^{7}$ published the geometric factors for $\left[\mathrm{TPPFe}(\mathrm{L})_{2}\right]^{+}$with pyridine or 4-MePy axial ligands. In the present work, however, it was found that the geometric factors for corresponding proton positions are different in the more hindered porphyrins of this study, most of which are expected to have ruffled porphyrinate rings. Therefore, the geometric factors for $\left[\mathrm{TMPFe}\left(4-\mathrm{NMe}_{2} \mathrm{Py}\right)_{2}\right]^{+}$were calculated from crystal structure data ${ }^{3}$ using the program Macromodel on a Silicon Graphics IRIS ${ }^{\mathrm{TM}}$ computer. Because of the strong $\mathrm{S}_{4}$ ruffling of the porphyrinate rings of $\left[\mathrm{TMPFe}(\mathrm{L})_{2}\right]^{+}, 3,4$ and the expectation of extremely rapid inversion of the ruffled porphyrinate ring, ${ }^{48}$ the two calculated $m-\mathrm{H}_{\mathrm{Ph}}$ (and two $o-\mathrm{CH}_{3}$ ) geometric factors were averaged. Table S8 compares the geometric factors for $\left[\mathrm{TPPFe}(\mathrm{L})_{2}\right]^{+}$obtained by $\mathrm{La} \mathrm{Mar}^{7}$ with those calculated for $\left[\mathrm{TMPFe}\left(4-\mathrm{NMe}_{2} \mathrm{Py}\right)_{2}\right]^{+}$(this work). For the most part, the differences are small, with only a $6.6 \%$ difference for the meta-protons of the porphyrin macrocycle. However, for the $o-\mathrm{H}_{\mathrm{Py}}$ position, the difference is $22.6 \%$. This difference can have a profound effect on the pseudocontact shift calculations, since the absolute value of the geometric factor for the ortho-pyridine protons, $259.5 \mathrm{x}$ $10^{-20} \mathrm{~cm}^{-3}$, is much larger than the value at any other proton position.

By factoring the pseudocontact shift of the $m-\mathrm{H}_{\mathrm{Ph}}$ of $\left[\mathrm{TMPFe}\left(4-\mathrm{Me}_{2} \mathrm{NPy}\right)_{2}\right]^{+}$using the geometric factors for the $m-\mathrm{H}_{\mathrm{Ph}}$ and $o-\mathrm{H}_{\mathrm{Py}}$ positions (Table S8) the estimated pseudocontact shift $\delta_{\mathrm{pc}}(o-$ $\left.\mathrm{H}_{\mathrm{Py}}\right)$ is $+29.3 \mathrm{ppm}$. The chemical shift of the ortho $-\mathrm{H}_{\mathrm{Py}}$ for $\left[\mathrm{TMPFe}\left(4-\mathrm{Me}_{2} \mathrm{NPy}\right)_{2}\right]^{+}$at $-60{ }^{\circ} \mathrm{C}$ is -7.38 ppm, and the diamagnetic shift of the same proton is $+1.50 \mathrm{ppm}\left(\right.$ Table $\left.\mathrm{S} 7^{43}\right)$, yielding $\delta_{\text {para }}\left(o-\mathrm{H}_{\mathrm{Py}}\right)=-$ $8.88 \mathrm{ppm}$. Thus the $o-\mathrm{H}_{\mathrm{Py}}$ contact shift of $\left[\mathrm{TMPFe}\left(4-\mathrm{Me}_{2} \mathrm{NPy}\right)_{2}\right]^{+}$at $-60{ }^{\circ} \mathrm{C}, \delta_{\text {con }}=-38.2 \mathrm{ppm}$. This point can then be placed on the $\delta_{\text {para }}\left(o-\mathrm{H}_{\mathrm{Py}}\right)$ vs. pyridine $\mathrm{pK}_{\mathrm{a}}\left(\mathrm{PyH}^{+}\right)$seen in Figure 6, now shown in Figure S21, such that the difference between $\delta_{\text {para }}=0$ and this point represents the contact contribution. If we then assume that the magnetic anisotropy changes sign at a $\mathrm{pK}_{\mathrm{a}}\left(\mathrm{PyH}^{+}\right)$of about 5 or 6, the pseudocontact shift should be nearly zero in the $\left[\mathrm{TMPFe}(\mathrm{Py})_{2}\right]^{+}$and $\left[\mathrm{TMPFe}(4-\mathrm{MePy})_{2}\right]^{+}$ 
complexes. Therefore, the pyridine and 4-methylpyridine $\delta_{\text {para }}$ data points represent the approximate contact shift at these $\mathrm{pK}_{\mathrm{a}}\left(\mathrm{PyH}^{+}\right)$values. Lines can now be drawn through the 4-Me $\mathrm{MPy}_{2}$ contact shift point and the Py (or 4-MePy) paramagnetic/contact shift point. This creates the situation shown in Figure S21, where the distance along the y-axis between zero and the experimental data point is the paramagnetic shift, the distance between zero and the line running through the $4-\mathrm{Me}_{2} \mathrm{NPy}$ contact shift point and the Py (blue line) or 4-MePy (green line) experimental data point is the contact shift (and the two lines measure the range of possible contact shifts as a function of $\left.\mathrm{pK}_{\mathrm{a}}\left(\mathrm{PyH}^{+}\right)\right)$, and the distance along the y-axis between the $\delta_{\text {para }}$ experimental data point and either of the contact shift lines is the pseudocontact shift. The pseudocontact shifts for the $o-\mathrm{H}_{\mathrm{Py}}$ resonances of all of the pyridine complexes can now be determined using this plot. The range of possible pseudocontact and contact shifts can then be calculated for all other resonances in the $\left[\mathrm{TMPFe}(\mathrm{L})_{2}\right]^{+}$complexes by factoring the geometric factors for the desired positions and then using Equation (3) to estimate the contact shifts at the desired position. This method leads to a range of possible contact shift values of -10.6 to -22.1 ppm for the $o-\mathrm{H}_{\mathrm{Py}}$ resonance of the [TMPFe$\left.(4-\mathrm{CNPy})_{2}\right]^{+}$complex.

Another method for separating the contact and pseudocontact contributions is by direct calculation using equation (5) for the pseudocontact shift. With the geometric factor for the pseudocontact shift being calculated from crystal structure data and the values of the constants in the first part of the equation being known at a given temperature, the only missing terms are the g-values. These may be obtained from EPR experiments run at $4.2 \mathrm{~K}$ for some of the compounds, assuming that they do not change as the temperature is raised to the range used for NMR measurements. To investigate this possible method, the complex with the purest known $\left(\mathrm{d}_{\mathrm{xy}}\right)^{2}\left(\mathrm{~d}_{\mathrm{xz}}, \mathrm{d}_{\mathrm{yz}}\right)^{3}$ ground state, $\left[\mathrm{TMPFe}(1-\mathrm{MeIm})_{2}\right]^{+}$, was considered. As discussed above, it can be assumed that the paramagnetic shift of the $m-\mathrm{H}_{\mathrm{Ph}}$ of the [TMPFe(1-MeIm) $\left.)_{2}\right]^{+}$complex is totally pseudocontact in nature, because of low or no spin density at the meso-carbons. Using the $m$ - $\mathrm{H}_{\mathrm{Ph}}$ geometric factor $\left(-17.8 \times 10^{20} \mathrm{~cm}^{-3}\right.$, 
Table S8), the EPR g-values for this complex $(2.89,2.33,1.57){ }^{3}$ and $\mathrm{T}=213.16 \mathrm{~K}$, the pseudocontact shift for the meta-protons is calculated to be $-1.91 \mathrm{ppm}$ at $-60{ }^{\circ} \mathrm{C}$. If this value is added to the observed chemical shift value of the $m-\mathrm{H}$ in the diamagnetic complex $(7.21 \mathrm{ppm})$ one obtains a calculated paramagnetic shift value of $5.30 \mathrm{ppm}$ for the $m-\mathrm{H}_{\mathrm{Ph}}$ at $-60{ }^{\circ} \mathrm{C}$ in $\left[\mathrm{TMPFe}(1-\mathrm{MeIm})_{2}\right]^{+}$. This corresponds very well with the observed chemical shift value at this temperature, which is 5.29 ppm, a value very similar to that of the 4-Me $\mathrm{MPy}_{2} \mathrm{NPmplex}$ at the same temperature, as mentioned above, 5.20 ppm, indicating that the assumption that $4-\mathrm{Me}_{2} \mathrm{NPy}$ is a "pseudo-imidazole" is a good one. And the close agreement between the calculated and observed chemical shifts shows that the assumption that the paramagnetic $m-\mathrm{H}_{\mathrm{Ph}}$ chemical shift is totally pseudocontact in nature is reasonable.

The g-values for the $\left[\mathrm{TMPFe}(4-\mathrm{CNPy})_{2}\right]^{+}$complex have been reported $\left(\mathrm{g}_{\perp}=2.53, \mathrm{~g}_{\|}=1.54\right),{ }^{4}$ and are included in Table 1. The ground state of this complex has the unpaired electron in the $d_{x y}$ orbital, which, if the porphyrinate ring is $S_{4}$ ruffled, can overlap with the $3 a_{2 u}(\pi)$ orbital, which has large coefficients at the meso positions. ${ }^{5}$ Therefore, electron density can delocalize to the metacarbons of the phenyl rings through bonds, resulting in a contact shift for the $m-\mathrm{H}_{\mathrm{Ph}}$ resonance. Since the only difference in the pseudocontact shift equation for the corresponding resonances in two different complexes is the g-anisotropy, factoring the pseudocontact shift of the $m-\mathrm{H}_{\mathrm{Ph}}$ of the 4$\mathrm{Me}_{2} \mathrm{NPy}$ complex using the g-anisotropy of the bis-4-Me ${ }_{2} \mathrm{NPy}$ and bis-4-CNPy complexes gives the same answer as that obtained by inserting the $\left[\mathrm{TMPFe}(4-\mathrm{CNPy})_{2}\right]^{+}$values into equation (6). The result is a value of $+1.84 \mathrm{ppm}$ for the pseudocontact shift of the $m-\mathrm{H}_{\mathrm{Ph}}$ of $\left[\mathrm{TMPFe}(4-\mathrm{CNPy})_{2}\right]^{+}$at -60 ${ }^{\circ} \mathrm{C}$.

The pseudocontact shift of all other resonances in the 4-CNPy complex can then be calculated by factoring the geometric factors for the $m-\mathrm{H}_{\mathrm{Ph}}$ and the other positions. With this method the pseudocontact shift for the $o-\mathrm{H}_{\mathrm{Py}}$ of the 4-CNPy ligand when bound to TMPFe(III) is calculated to be 
$-26.8 \mathrm{ppm}$ at $-60{ }^{\circ} \mathrm{C}$. With a paramagnetic shift of $-32.5 \mathrm{ppm}$ measured for this resonance the contact shift is calculated to be $-5.7 \mathrm{ppm}$. This value is quite different from the $-22.1 \mathrm{or}-10.6 \mathrm{ppm}$ shift for the $o-\mathrm{H}_{\mathrm{Py}}$ resonance of [TMPFe$\left.(4-\mathrm{CNPy})_{2}\right]^{+}$using the $\delta_{\text {con }}$ blue or green lines in Figure S21. Because the $\left[\mathrm{TMPFe}(4-\mathrm{CNPy})_{2}\right]^{+}$complex has the unpaired electron in the $\mathrm{d}_{\mathrm{xy}}$ orbital, it is expected that the contact term should be small, because this orbital does not have the proper symmetry to overlap with the $\mathrm{p}_{\pi}$ orbital of the pyridine axial ligand. Thus, the paramagnetic shift would be dominated by the pseudocontact term. This suggests that the $-5.7 \mathrm{ppm}$ value may be more representative of the contact shift. However, spin polarization from Fe(III) to the axial ligand nitrogen to the ortho-carbon of the pyridine ligand could contribute to an observed contact shift, which should be negative at the $o-\mathrm{H}_{\mathrm{Py}}$. Therefore, it is not possible to say which of the three possible contact shifts $(-5.7,-10.6$ or $-22.1 \mathrm{ppm})$ is most reasonable.

The weakness of this latter method is that the EPR spectra of all of these [TMPFe(L) $]_{2}^{+}$ complexes, except for $\mathrm{L}=1$-MeIm, are strongly g-strained such that it is difficult to measure any but the largest g-value of each complex accurately. For the TMP case, only two compounds give completely resolved EPR spectra at $4.2 \mathrm{~K}$, these being the previously discussed [TMPFe(4-CNPy $\left.)_{2}\right]^{+4}$ and $\left[\mathrm{TMPFe}(1-\mathrm{MeIm})_{2}\right]^{+},{ }^{3}$ which give axial and rhombic spectra, respectively. All other complexes in this study give "large $g_{\max }$ " signals, which makes it difficult to obtain the three g-values required for use of equation (6). In some of these complexes, magnetic Mössbauer spectroscopy may provide estimates of all three g-values. ${ }^{1,3,30,32}$ In the meantime, we can consider the possibility that if 4$\mathrm{Me}_{2} \mathrm{NPy}$ is truly a "pseudo-imidazole", then we might use the g-values for the 1-MeIm complex to obtain the g-anisotropy for the 4-Me $2 \mathrm{NPy}$ complex. For the 1-MeIm complex, $\left(\mathrm{g}_{\|}{ }^{2}-\mathrm{g}_{\perp}{ }^{2}\right)$ is calculated to be 4.39 , which leads to a calculated pseudocontact shift of $27.8 \mathrm{ppm}$, and a derived contact shift of $-36.7 \mathrm{ppm}$. This value is very similar to that obtained from the factoring method discussed above that 
was based upon the assumption that the paramagnetic shift of the $m-\mathrm{H}_{\mathrm{Ph}}$ of $\left[\mathrm{TMPFe}\left(4-\mathrm{Me}_{2} \mathrm{NPy}\right)_{2}\right]^{+}$is totally pseudocontact in nature $(-38.2 \mathrm{ppm})$, the blue diamond in Figure S21.

Although the two smaller g-values for [TMPFe $\left.\left(4-\mathrm{NMe}_{2} \mathrm{Py}\right)_{2}\right]^{+}$could not be obtained from the EPR spectrum, from the fit of the Mössbauer spectrum of [TMPFe(4-NMe $2 \mathrm{Py}] \mathrm{ClO}_{4}$ recorded at $4.2 \mathrm{~K}$ in a 6 Tesla applied magnetic field, the g-values could be obtained: ${ }^{3} 3.44$ for $\mathrm{g}_{\mathrm{z}}, 1.80$ for $\mathrm{g}_{\mathrm{y}}$, and 0.92 for $\mathrm{g}_{\mathrm{x}}$. Using these g-values in the pseudocontact shift equation (equation (6)) for the $o$ - $\mathrm{H}_{\mathrm{Py}}$ shifts of $\left[\mathrm{TMPFe}\left(4-\mathrm{Me}_{2} \mathrm{NPy}\right)_{2}\right]^{+}$at $-60{ }^{\circ} \mathrm{C}$ results in a pseudocontact shift of $61.9 \mathrm{ppm}$. Using this and Equation (3), a contact shift value of $-69.3 \mathrm{ppm}$ is calculated. By placing this value (red point at $\left.\mathrm{pK}_{\mathrm{a}}\left(\mathrm{PyH}^{+}\right)=9.7\right)$ on the $\delta_{\text {para }}$ versus $\mathrm{pK}_{\mathrm{a}}\left(\mathrm{PyH}^{+}\right)$plot of Figure $\mathrm{S} 21$ and drawing a line from this low temperature "EPR" data point for the 4-Me $2 \mathrm{NPy}$ complex to the "EPR" data point (red point at $\left.\mathrm{pK}_{\mathrm{a}}\left(\mathrm{PyH}^{+}\right)=1.1\right)$ for the 4-CNPy complex we obtain the red line in Figure $\mathrm{S} 21$. This line represents the dependence of the contact shift on pyridine basicity that would be calculated if the $4.2 \mathrm{~K}$ ganisotropy value were valid at the temperatures where the NMR spectra were recorded, whereas the blue and green lines represent the contact shift calculated from the NMR shifts from which an "effective" g-anisotropy value of 4.63 was obtained for the $\left[\mathrm{TMPFe}\left(4-\mathrm{Me}_{2} \mathrm{NPy}\right)_{2}\right]^{+}$complex based upon the assumption that the $m-\mathrm{H}_{\mathrm{Ph}}$ paramagnetic shift is totally due to the pseudocontact term. The red line that is based on $4.2 \mathrm{~K} \mathrm{EPR}$ parameters only suggests that the point at which the g-anisotropy changes sign is between the $\mathrm{pK}_{\mathrm{a}}\left(\mathrm{PyH}^{+}\right)$of $\mathrm{Py}$ and 3-ClPy instead of between that of Py and 4-MePy.

The problem with the EPR-only red line is that it assumes that the g-anisotropy values at $4.2 \mathrm{~K}$ do not change with temperature. Although Goff has presented evidence that this is the case for bisimidazole complexes, ${ }^{24}$ the blue and green lines derived from the assumption that the $m-\mathrm{H}_{\mathrm{Ph}}$ paramagnetic shift of $\left[\mathrm{TMPFe}\left(4-\mathrm{Me}_{2} \mathrm{NPy}\right)_{2}\right]^{+}$is totally pseudocontact in nature and that $\delta_{\mathrm{pc}}=0$ for either pyridine or 4-methylpyridine, respectively, indicate that the assumption that the g-anisotropies are not temperature dependent (red line) is not realistic. It can be reasoned that as the temperature is 
raised the effective g-anisotropy changes due to temperature-dependent factors such as the secondorder Zeeman contribution, ${ }^{23}$ as well as the existence of thermally-accessible excited states of different spin multiplicity than the ground state. The result would thus be that the line representing the contact shift in a $\delta_{\mathrm{para}} o-\mathrm{H}_{\mathrm{Py}}$ vs. $\mathrm{pK}_{\mathrm{a}}\left(\mathrm{PyH}^{+}\right)$plot becomes less and less steep as the temperature is increased. If this is the case, then even though the point where the g-anisotropy changes sign may not be between that of pyridine and 4-methylpyridine, it should remain reasonably close to that point. The blue or green lines in Figure S21 would therefore be better first approximations of the contact shift at $-60^{\circ} \mathrm{C}$ for the $\left[\mathrm{TMPFe}(\mathrm{L})_{2}\right]^{+}$complexes than the red line, and we consider the green line to be the best, for it closely approximates the line that would be drawn if the g-anisotropy of $\left[\mathrm{TMPFe}(4-\mathrm{CNPy})_{2}\right]^{+}$were approximately unchanged with temperature and the 1-MeIm complex of TMP were used instead of that of 4-Me $\mathrm{M}_{2} \mathrm{NPy}$ complex. This would simply mean that the g-anisotropies change only slightly with temperature, which seems reasonable in view of the calculations presented in reference 23. It is this green contact shift line, then, that is used to calculate the $o-\mathrm{H}_{\mathrm{Py}}$ contact shifts for all other pyridine complexes of TMPFe(III), and, using the geometric factors, the pyrrole- $\mathrm{H}$ and $m$ - $\mathrm{H}_{\mathrm{Ph}}$ contact shifts for the same complexes, as presented in Table S9.

In Table S9 the values predicted for the contact and pseudocontact shifts of the [TMPFe $\left.(\mathrm{L})_{2}\right]^{+}$ complexes, calculated using the green contact shift line in Figure S21, are given. For the pyrrole-H, the calculations result in negative values for the contact shifts, which are predicted for $\pi$ delocalization. ${ }^{6}$ The contact shift values for the pyrrole-H of the higher-basicity pyridine complexes $\left(-27.7 \mathrm{ppm}\right.$ for $\left.\left[\mathrm{TMPFe}\left(4-\mathrm{Me}_{2} \mathrm{NPy}\right)_{2}\right]^{+}\right)$are larger than those for the lower-basicity pyridine complexes $\left(-14.6 \mathrm{ppm}\right.$ for $\left.\left[\mathrm{TMPFe}(4-\mathrm{CNPy})_{2}\right]^{+}\right)$. Since the unpaired electron is in the $\mathrm{d}_{\mathrm{xz}}, \mathrm{d}_{\mathrm{yz}}$ degenerate orbital set (which has the proper symmetry for overlap with the porphyrin $3 e(\pi)$ orbitals, with large coefficients at the pyrrole positions) in the ground state of the higher-basicity pyridine $\left[\mathrm{TMPFe}(\mathrm{L})_{2}\right]^{+}$complexes, $\delta_{\text {con }}$ is predicted to be larger in magnitude for them than for the lower- 
basicity pyridine $\left[\mathrm{TMPFe}(\mathrm{L})_{2}\right]^{+}$complexes, where the unpaired electron is in the $\mathrm{d}_{\mathrm{xy}}$ orbital in the ground state.

(57) La Mar, G. N.; Walker, F. A. J. Am. Chem. Soc. 1973, 95, 1782-1790. 
Table S8. Geometric factors published by La Mar et al. ${ }^{7}$ compared with those calculated from the structure of $\left[\mathrm{TMPFe}\left(4-\mathrm{Me}_{2} \mathrm{NPy}_{2}\right] \mathrm{ClO}_{4},{ }^{3}\right.$ used in this work.

\begin{tabular}{|c|c|c|c|c|c|}
\hline \multicolumn{3}{|c|}{ La Mar etal. } & \multicolumn{3}{|c|}{ This work } \\
\hline \multirow{3}{*}{ TPP } & Position & Factor* & \multirow{3}{*}{ TMP } & \multirow{2}{*}{$\begin{array}{l}\text { Position } \\
m-\mathrm{H}\end{array}$} & \multirow{2}{*}{$\begin{array}{l}\text { Factor* } \\
-17.8\end{array}$} \\
\hline & $m-\mathrm{H}$ & -16.7 & & & \\
\hline & $p-\mathrm{CH}_{3}$ & -11.0 & & $p-\mathrm{CH}_{3}$ & -11.6 \\
\hline \multirow{5}{*}{ Pyridine } & pyrrole-H & -70.3 & \multirow{5}{*}{ Pyridine } & pyrrole-H & -76.4 \\
\hline & & & & $o-\mathrm{CH}_{3}$ & -16.1 \\
\hline & $o-\mathrm{H}$ & 211.6 & & $o-\mathrm{H}$ & 259.5 \\
\hline & $m-\mathrm{H}$ & 115 & & $m-\mathrm{H}$ & 122.2 \\
\hline & & & & $p-\mathrm{NCH}_{3}$ & 47.4 \\
\hline
\end{tabular}

*Geometric factors given are $\times 10^{20} \mathrm{~cm}^{-3}$. 
范

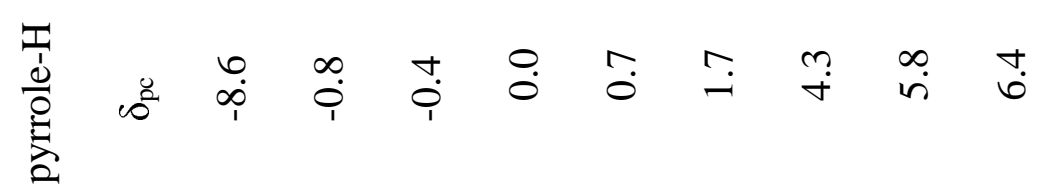

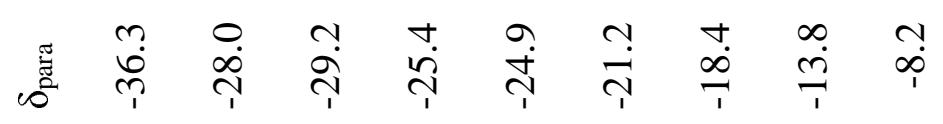

$\frac{\dot{d}}{\frac{x}{0}}$

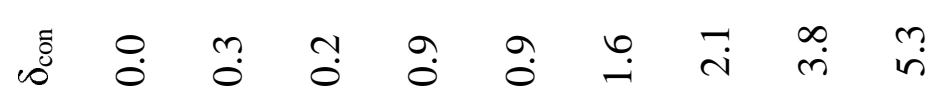

$\stackrel{2}{=}$

ฮั

¿

웅

స

ई

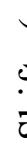

㝳

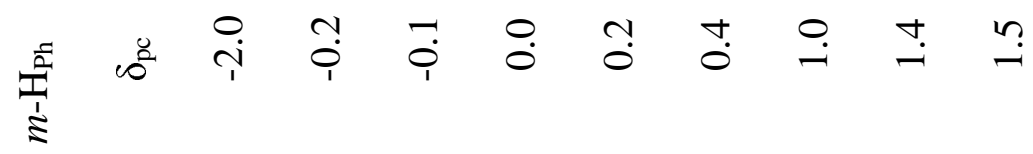

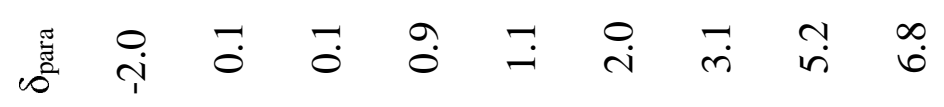

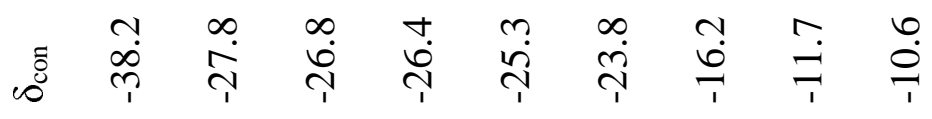

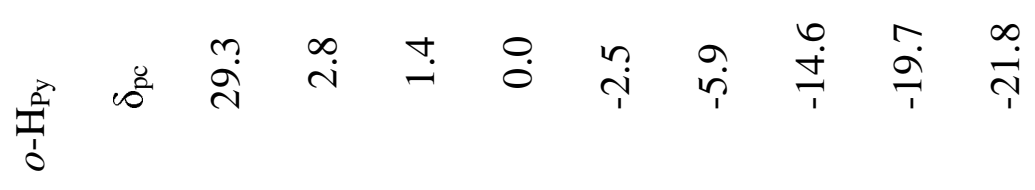

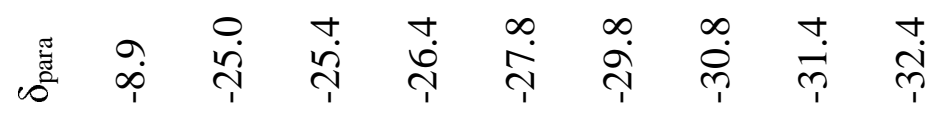

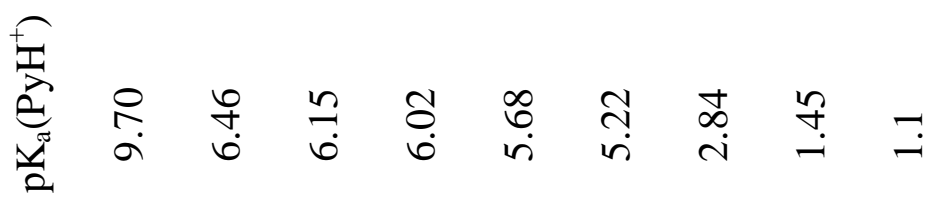

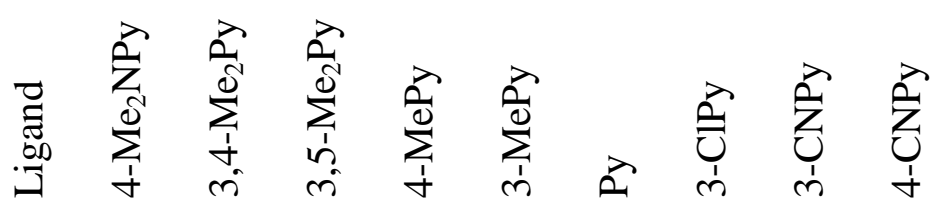




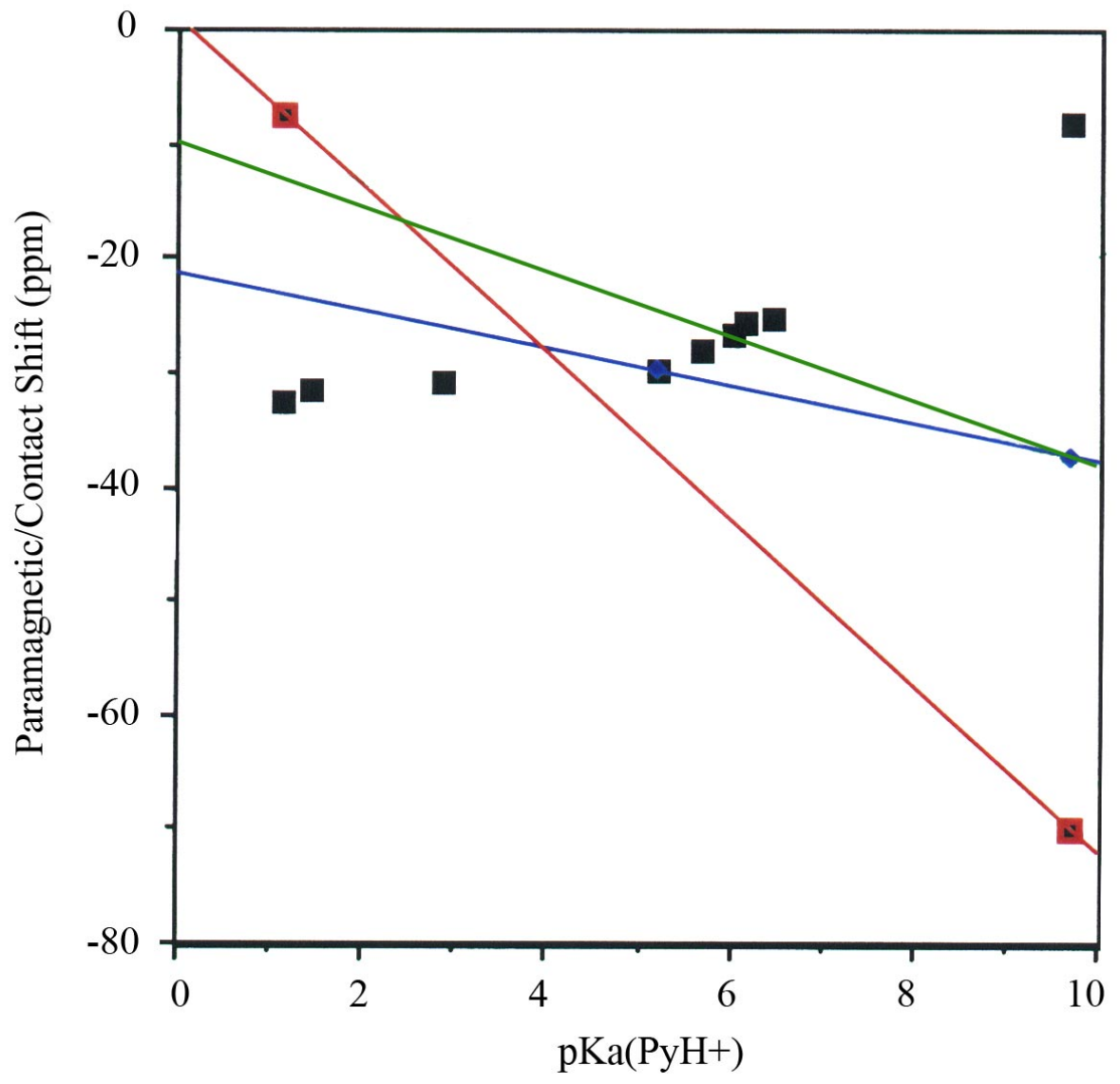

Figure S21. Paramagnetic shifts at $-60{ }^{\circ} \mathrm{C}$ vs. $\mathrm{pK}_{\mathrm{a}}\left(\mathrm{PyH}^{+}\right)$for the $o-\mathrm{H}_{\mathrm{Py}}$ of the $\left[\mathrm{TMPFe}(\mathrm{L})_{2}\right]^{+}$complexes as shown in Figure 6, with three fits. The blue line represents the contact shift calculated from the meta-H pseudocontact shift of $\left[\mathrm{TMPFe}\left(4-\mathrm{Me}_{2} \mathrm{NPy}\right)_{2}\right]^{+}$and the assumption that for the Py complex, $\delta_{\text {para }}=\delta_{\text {con }}$, while the green line represents the same contact shift for the 4-Me $2 \mathrm{NPy}$ complex and the assumption that for the 4-MePy complex, $\delta_{\text {para }}=\delta_{\text {con }}$. The red line represents the contact shift calculated from the EPR gvalues of $\left[\mathrm{TMPFe}(4-\mathrm{CNPy})_{2}\right]^{+}$and the g-values obtained from the magnetic Mössbauer spectrum ${ }^{3}$ of $\left[\mathrm{TMPFe}\left(4-\mathrm{Me}_{2} \mathrm{NPy}\right)_{2}\right]^{+}$at $4.2 \mathrm{~K}$. The green contact shift line is used in the calculations of $\delta_{\text {con }}$ and $\delta_{\mathrm{pc}}$ in Table S9. 